\title{
A Reference List of Phenolic Compounds (Including Stilbenes) in Grapevine (Vitis vinifera L.) Roots, Woods, Canes, Stems, and Leaves
}

\author{
Piebiep Goufo ${ }^{1, * \mathbb{D}}$, Rupesh Kumar Singh ${ }^{2}$ and Isabel Cortez ${ }^{1}$ \\ 1 Centre for the Research and Technology of Agro-Environment and Biological Sciences, Departamento de \\ Agronomia, Universidade de Trás-os-Montes e Alto Douro, Quinta de Prados, 5000-801 Vila Real, Portugal; \\ icortez@utad.pt \\ 2 Centro de Química de Vila Real, Universidade de Trás-os-Montes e Alto Douro, Quinta de Prados, \\ 5000-801 Vila Real, Portugal; rupesh@utad.pt \\ * Correspondence: pgoufo@utad.pt
}

Received: 15 April 2020; Accepted: 5 May 2020; Published: 8 May 2020

\begin{abstract}
Due to their biological activities, both in plants and in humans, there is a great interest in finding natural sources of phenolic compounds or ways to artificially manipulate their levels. During the last decade, a significant amount of these compounds has been reported in the vegetative organs of the vine plant. In the roots, woods, canes, stems, and leaves, at least 183 phenolic compounds have been identified, including 78 stilbenes $(23$ monomers, 30 dimers, 8 trimers, 16 tetramers, and 1 hexamer), 15 hydroxycinnamic acids, 9 hydroxybenzoic acids, 17 flavan-3-ols (of which 9 are proanthocyanidins), 14 anthocyanins, 8 flavanones, 35 flavonols, 2 flavones, and 5 coumarins. There is great variability in the distribution of these chemicals along the vine plant, with leaves and stems/canes having flavonols ( $83.43 \%$ of total phenolic levels) and flavan-3-ols (61.63\%) as their main compounds, respectively. In light of the pattern described from the same organs, quercetin-3-O-glucuronide, quercetin-3-O-galactoside, quercetin-3-O-glucoside, and caftaric acid are the main flavonols and hydroxycinnamic acids in the leaves; the most commonly represented flavan-3-ols and flavonols in the stems and canes are catechin, epicatechin, procyanidin $\mathrm{B} 1$, and quercetin-3-O-galactoside. The main stilbenes (trans- $\varepsilon$-viniferin, trans-resveratrol, isohopeaphenol/hopeaphenol, vitisin B, and ampelopsins) accumulate primarily in the woods, followed by the roots, the canes, and the stems, whereas the leaves, which are more exposed to environmental stresses, have a low concentration of these compounds. Data provided in this review could be used as (i) a metabolomic tool for screening in targeted and untargeted analyses and (ii) a reference list in studies aimed at finding ways to induce naturally occurring polyphenols on an industrial scale for pant and human disease control.
\end{abstract}

Keywords: bioactive compounds; vegetative organs; antioxidant activity; Vitis vinifera; secondary metabolites; polyphenol database; grapevine

\section{Introduction}

Grapevine (Vitis vinifera L.) is a perennial woody fruit crop used for wine, juice, fresh consumption (table grapes), dried fruit, and distilled liquor [1-8]. Most of the premium cultivars are highly susceptible to several pathogenic microorganisms [6,9-13]. In the past decades, the understanding of grapevine/pathogen interactions has focused on the molecular response of the host, and several metabolites, proteins, and gene/gene products have been identified as putative biomarkers of grapevine disease tolerance [14-18]. In particular, the importance of phenolic compounds as natural fungicides implicated in the resistance of some grapevine cultivars to fungi, oomycetes, bacteria, phytoplasma, and viruses have been highlighted by several authors; one of the most known properties of these 
compounds is their antioxidative activity, whereby they are able to scavenge free radicals and positively influence health outcomes [5,19-31]. Plants have evolved a variety of mechanisms using phenolic compounds, including the formation of a protective shield against ultraviolet (UV) radiation. Therefore, the compounds produced by highly resistant varieties are of great interest for the development of improved crops, natural spray reagents, and new dietary supplements or pharmaceuticals [5,19,32-36].

In $V$. vinifera, many studies have been published that reported on the concentration of phenolics in berry-containing foods and their impact on human health $[18,35]$. Indeed, several databases are available for the levels of phenolic compounds in the fruits (e.g., eBASIS, Phenol-Explorer), but none are available for non-edible parts of $V$. vinifera. Recently, the stems and canes of this economically important genus have been reported as an untapped source of health-promoting compounds [16,17,31,35-39]. Because of this, numerous efforts for isolation, identification, and quantification of phenolic compounds in the vegetative organs of grapevine have been ongoing. In order to properly design valorization strategies, the precise chemical composition of these vegetative materials has to be known. In this review, a more thorough understanding of the chemical diversity of polyphenols within $V$. vinifera vegetative organs is provided, which will be useful in this endeavor. The review includes an overview of compounds identified in the roots, cordon and trunk woods, canes, stems, and leaves with their mass and UV spectrum patterns, followed by an estimation of their levels. It concludes with a brief presentation of factors affecting the biosynthesis and accumulation of these compounds. The fallout of such data is multifaceted and will surely contribute to advancing the scientific knowledge in the field.

\section{The Vegetative Organs of the Vine Plant}

Grapevine is a climber whose growth in the vineyard is maintained with pruning in order to control the quantity and quality of the grapes [40]. Like any other plant, grapevine has vegetative and reproductive organs. The vegetative organs of vine include the roots and five parts extending from the root system and visible aboveground: trunk, cordons, canes, stems, and leaves. These organs play a key role in light energy capture via photosynthesis, as well as water and nutrient absorption as regulated by transportation.

\subsection{Roots}

The roots of a vine plant are multi-branched structures that grow to various depths into the soil on the basis of the variety (rootstock), and are responsible for anchoring the plant to the ground $[12,23,29,30,41,42]$.

\subsection{Woods}

In the literature, the "wood" refers to samples obtained from the trunk and the cordons. The trunk is composed of sleeves of conductive tissues, most notably the phloem and the xylem [13,43-45]. Cordons or "arms" are extensions of the trunk and the parts where canes (one-year-old wood containing between 8 and 15 buds) and spurs (one-year-old wood containing between two and three buds) originate [12].

\subsection{Canes}

The terms "stems", "canes", "stalks", and "shoots" are sometimes used interchangeably in the literature. For the purpose of this review and on the basis of the literature surveyed, the shoot is the new green growth that develops from buds located on the cordons [24,25,46-49]. Once the leaves fall from the vine at the beginning of the dormant season, the brown and harden/woody shoot is considered a cane, which represents a large source of waste derived from the wine industry [40,50-52].

\subsection{Stems}

The stem consists of the stalk extending out to hold the grape cluster (also known as the bunchstem) and the "stem" of the individual grape berry (also called the pedicel by some authors) [9,37,50,53-58]. 


\subsection{Leaves}

Leaves are the most visible parts of the canopy and consist of the blade (the broad, flat part of the leaf designed to absorb sunlight and $\mathrm{CO}_{2}$ ), and the petiole (the stem-like structure that connects the leaf to the shoot) $[4,5,11,19,22,32,59-64]$.

\section{Extraction, Separation, and Identification of Phenolic Compounds in Grapevine}

In grapevine varieties, polyphenols are present as constitutive compounds of the lignified organs (roots, canes, seeds, stems, ripe cluster stems) and/or as induced substances in leaves and berries. In the frame of a long-term project aimed at investigating the physiological and molecular responses of grapevine to trunk diseases [15], several papers that contained the terms "grapevine, grape, vine, vineyard, or vitis" in their titles, plus one of the following terms: "phenolic, polyphenol, flavonoid, anthocyanin, proanthocyanidin, tannin, stilbene, stilbenoid, bioactive, bioactivity, antioxidant, antioxidative, metabolite, metabolic, metabolomic, metabolome, leaf, stem, root, wood, cordon, cane, trunk, phytoalexin, defense, resistance", or terms related to the specific diseases and pathogens of grapevine, were retrieved from citation databases; 80 papers were analyzed that primarily reported on the presence and levels of polyphenols in the vegetative organs (Tables S1 and S2). The term "polyphenol" is used in this review to indicate both the compounds with a second aromatic ring and those arising from the polymerization of flavonoidic/catechin units. Despite their structural diversity, all polyphenols share a common structure element, which consists of a benzene ring to which more than one hydroxyl group is attached [65].

The surveyed literature shows that many extraction methods have been tested, and that several analytical methods using numerous techniques have been developed for the investigation of polyphenols in grapevine, including high-performance liquid chromatography (HPLC) coupled with diode array detection (LC-DAD), HPLC coupled with mass spectrometry (LC-MS, LC-MS/MS), and nuclear magnetic resonance (NMR) $[24,28,36,66,67]$. Different advantages and disadvantages are associated with each analytical system. Analysis by HPLC-DAD (or HPLC/UV-VIS) is limited by similar or identical absorption maxima of target compounds belonging to the same structural class of polyphenols. Other problems such as lack of baseline resolution, leading to overestimation of individual compound levels, may exist, along with poor sensitivity $[16,17,36]$. Because of its high selectivity, LC-MS/MS with electrospray ionization (ESI), atmospheric pressure photoionization (APPI), or chemical ionization (APCI) enables the sensitive and simultaneous detection and identification of a large number of (even co-eluting) compounds from a single chromatogram and is therefore the method of choice when libraries are available. MS also enables reductions in the process of sample preparation from extracts $[10,68]$. NMR, on the other hand, is a non-destructive high throughput method that allows metabolite identification and quantification. It is, however, significantly less sensitive than MS, although more reproducible, especially in long-term studies where samples collected and analyzed over different time periods have to be compared. NMR is also an invaluable tool for the de novo structure determination of compounds [16,59]. In all cases, however, precise conditions are required to achieve a complete qualitative survey of all metabolites over a significant dynamic range in a complex plant extract. Depending on the optimization of extraction and detection parameter settings, two large groups of chemical compounds with phenolic characteristics-that are classified into several structure classes-are clearly delineated in grapevine and are separately discussed in this paper.

The first group comprises phenolic acids (hydroxybenzoic and hydroxycinnamic acids), flavonoids (e.g., flavonols, anthocyanins, proanthocyanidins), and coumarins, which are usually present as preformed compounds in the tissues. Indeed, HPLC in gradient mode on reversed phase C18 columns provides a means to separate most of these compounds in a single chromatography run without the need for derivatization. Due to their structural complexity, however, proanthocyanidins are more easily separated alone by hydrophilic interaction liquid chromatography (HILIC) according their degree of polymerization, or by reverse-phase chromatography, although some of them coelute [69]. 
The second group is constituted of stilbenic compounds (stilbenes that bear the core structure of 1,2-diphenylethylene and stilbenoids that are hydroxylated derivatives of stilbenes). Several of these compounds are produced naturally by several plants upon attack by pathogens $[8,14,70,71]$. Because of their dynamic behavior as responses to stresses, the detection of stilbenes requires methods that can be used for monitoring their differential response in various phytopathologic situations $[61,71]$. Their extraction generally requires specialized instrumentation and expertise, for instance, sample cleaning techniques such as solid phase extraction (SPE), sample dilution, selective extraction, or use of stable isotopes. Most of the qualitative or quantitative analytical studies of stilbenes are performed with HPLC and in an increasing sensitivity order UV, fluorescence (FD), electrochemical (ECD), or MS detection [36,50,52]. A method for the simultaneous separation of proanthocyanidins and stilbenoids has been reported, using a comprehensive bi-dimensional chromatography, with a diol stationary phase in the first dimension and a C18 stationary phase in the second dimension [50,72].

\section{Polyphenols (Excluding Stilbenes) Identified in the Vegetative Organs of Grapevine}

Phenolic compounds produced by grapevine range from cell wall-thickening compounds such as lignin and tannins, to specialized compounds such as phenolic acids and flavonoids. The chemical characterization of these compounds is based on analysis of different groups of components individually by LC-MS, mainly in negative ionization mode, although some LC-MS methods in positive-ion mode have been reported [16]. With high-resolution MS, compounds are identified by processing raw data with specific algorithms to calculate molecular formulae on the basis of the monoisotopic mass of the $[\mathrm{M}-\mathrm{H}]^{-}$ion and the relative abundances and distances (spacing) of $\mathrm{m} / \mathrm{z}$ signals measured in the isotopic pattern. Metabolites are then identified by searching in the available MS databases, in comparison with UV spectra patterns reported in the literature [16]. In Table 1, a database specific to grapevine phenolics containing 105 metabolites, including their specific MS and UV information, is provided.

\subsection{Hydroxycinnamic Acids}

The phenylpropanoid pathway starts with the aromatic amino acid phenylalanine and leads to derivatives with one, two, or more aromatic rings (C6), each ring with a characteristic substitution pattern, and with different modifications of the propane residue of phenylalanine (C3) [35]. At least 15 hydroxycinnamic acids (moiety $\mathrm{C} 6-\mathrm{C} 3$ ) have been identified in the vegetative organs of grapevine, with different degrees of hydroxylation and methylation of $\mathrm{C} 6$. These include caftaric, coutaric, chlorogenic, chicoric, fertaric, caffeic, $p$-coumaric, ferulic, sinapic, and cinnamic acids, and some of their derivatives, that is, 1-O-sinapoyl- $\beta$-D-glucose, 1-O-(4-coumaroyl)-glucose, 1-caffeoyl- $\beta$ - $\mathrm{D}$-glucose (reported as caffeic acid derivative by some authors), ferulic acid pentose (reported as ferulic acid derivative by some authors), and a caftaric acid isomer (Table 1) [20,32,46,47,53,73,74].

\subsection{Hydroxybenzoic Acids}

The cleavage of a C2 fragment from the aliphatic side chain of $p$-coumaric acid leads to hydroxybenzoic acids (C6-C1) [35], and nine have been reported in the vegetative organs of grapevine: quinic, gallic, protocatechuic, $p$-hydroxybenzoic, gentisic, $\gamma$-resorcylic, vanillic, syringic, and ellagic acids, mostly detected in the leaves (Table 1) $[4,32,47,73,75]$. 
Table 1. Polyphenols (excluding stilbenes) in the vegetative organs of the grapevine plant.

\begin{tabular}{|c|c|c|c|c|c|c|c|c|c|c|c|c|c|}
\hline ID $^{1}$ & Compound Group & $\begin{array}{l}\text { Compound } \\
\text { Name }^{1}\end{array}$ & $\begin{array}{l}\text { Chemical } \\
\text { Formula }^{2}\end{array}$ & $\begin{array}{c}\text { MW } \\
(\mathrm{g} / \mathrm{mol})\end{array}$ & {$[\mathrm{M}-\mathrm{H}]-$} & $\begin{array}{c}\text { Main MS/MS } \\
\text { Fragments }(\mathrm{m} / \mathrm{z}){ }^{3,4}\end{array}$ & $\lambda \max \left(\mathrm{CH}_{3} \mathrm{OH}\right)(\mathrm{nm})$ & Detection Mode ${ }^{5}$ & \multicolumn{5}{|c|}{ Tissue Distribution ${ }^{6}$} \\
\hline & & & & & & & & & LEAVES & STEMS & CANES & WOODS & ROOTS \\
\hline 1 & Hydroxybenzoic acid & Quinic acid & C7H12O6 & 192.167 & 191 & $111,173,85,127$ & 308,280 & MS & $\checkmark$ & & & & \\
\hline 2 & Hydroxybenzoic acid & Gallic acid & C7H6O5 & 170.120 & 169 & $125,124,79,51$ & 278,214 & MS, NMR, DAD & $\checkmark r$ & $\checkmark$ & $\checkmark$ & & \\
\hline 4 & Hydroxybenzoic acid & Protocatechuic acid & $\mathrm{C} 7 \mathrm{H} 6 \mathrm{O} 4$ & 154.121 & 153 & 109,108 & 297,258 & MS & $\checkmark$ & & $\checkmark$ & & \\
\hline 7 & Hydroxybenzoic acid & $p$-Hydroxybenzoic acid & $\mathrm{C} 7 \mathrm{H} 6 \mathrm{O} 3$ & 138.122 & 137 & $93,60,79,108,118,137$ & $272,310 \mathrm{sh}$ & MS & $\checkmark$ & & $\checkmark$ & & \\
\hline 8 & Hydroxybenzoic acid & Gentisic acid & C7H6O4 & 154.121 & 153 & $109,81,42,108$ & $281,228,330 \mathrm{sh}$ & MS & $\checkmark$ & & & & \\
\hline 9 & Hydroxybenzoic acid & $\gamma$-Resorcylic acid & $\mathrm{C} 7 \mathrm{H} 6 \mathrm{O} 4$ & 154.121 & 153 & 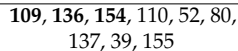 & 313,245 & MS & $\checkmark$ & & & & \\
\hline 30 & Hydroxybenzoic acid & Vanillic acid & $\mathrm{C} 8 \mathrm{H} 8 \mathrm{O} 4$ & 168.149 & 167 & $123,152,108,91$ & 292,260 & MS, NMR, DAD & $\checkmark$ & & $\checkmark$ & & \\
\hline 36 & Hydroxybenzoic acid & Syringic acid & C9H10O5 & 198.174 & 197 & $182,153,167,138$ & 276 & MS, NMR, DAD & $\checkmark$ & $\checkmark$ & $\checkmark$ & & \\
\hline 50 & Hydroxybenzoic acid & Ellagic acid & C14H608 & 302.194 & 301 & $284,300,257,229,184$ & $367,256,301 \mathrm{sh}$ & MS & $\checkmark$ & & $\checkmark$ & & \\
\hline 14 & Hydroxycinnamic acid & 1-O-Sinapoyl- $\beta$-D-glucose & $\mathrm{C} 17 \mathrm{H} 22 \mathrm{O} 10$ & 386.353 & 385 & $\begin{array}{c}223,205,341,265,190, \\
179,119,247\end{array}$ & 282 & MS & $\checkmark$ & & & & \\
\hline 16 & Hydroxycinnamic acid & 1-O-(4-Coumaroyl)-glucose & $\mathrm{C} 15 \mathrm{H} 18 \mathrm{O} 8$ & 326.301 & 325 & $\begin{array}{l}163,145,119,187,265, \\
205\end{array}$ & 322 & MS & $\checkmark$ & $\checkmark$ & & & \\
\hline 20 & Hydroxycinnamic acid & 1-Caffeoyl- $\beta$-D-glucose & C15H18O9 & 342.300 & 341 & $\begin{array}{l}\mathbf{1 7 9}, \mathbf{1 6 1}, 143,149,131, \\
135\end{array}$ & $290,304 \mathrm{sh}, 328$ & MS & $\checkmark$ & $\checkmark$ & & & \\
\hline 21 & Hydroxycinnamic acid & Ferulic acid pentose & NA & NA & 325 & $\mathbf{1 4 9}, 178,193$ & 326,275 & MS & $\checkmark$ & $\checkmark$ & & & \\
\hline 22 & Hydroxycinnamic acid & Caftaric acid isomer & $\begin{array}{l}\mathrm{C} 13 \mathrm{H} 11 \mathrm{O} 9 \\
\end{array}$ & 311.224 & 311 & $\mathbf{1 7 9}, 135,149$ & 325,286 & MS & $\checkmark$ & & & & \\
\hline 24 & Hydroxycinnamic acid & Caftaric acid & $\mathrm{C} 13 \mathrm{H} 12 \mathrm{O} 9$ & 312.230 & 311 & $\begin{array}{l}\mathbf{1 7 9 ,} 135, \mathbf{1 4 9 ,}, 267,161, \\
237\end{array}$ & $326,298 \mathrm{sh}, 243$ & MS, NMR, DAD & $\checkmark$ & $\checkmark$ & $\checkmark$ & & \\
\hline 27 & Hydroxycinnamic acid & Coutaric acid & $\mathrm{C} 13 \mathrm{H} 12 \mathrm{O} 8$ & 296.231 & 295 & $163,149,119$ & $316,234,300 \mathrm{sh}$ & MS, DAD & $\checkmark$ & & $\checkmark$ & & \\
\hline 28 & Hydroxycinnamic acid & Chlorogenic acid & $\mathrm{C} 16 \mathrm{H} 18 \mathrm{O} 9$ & 354.311 & 353 & $\begin{array}{c}191,179,135,161,335 \\
172,284\end{array}$ & $328,244,303 \mathrm{sh}$ & MS, DAD & $\checkmark$ & & & & \\
\hline 31 & Hydroxycinnamic acid & Chicoric acid & $\mathrm{C} 22 \mathrm{H} 18 \mathrm{O} 12$ & 474.374 & 473 & $\begin{array}{c}311, \mathbf{2 9 3}, \mathbf{1 7 9}, 149,135 \\
219\end{array}$ & $328,305 \mathrm{sh}, 279$ & MS & & $\checkmark$ & & & \\
\hline 32 & Hydroxycinnamic acid & Fertaric acid & C14H14O9 & 326.259 & 325 & $193,175,149,281,134$ & 314,279 & MS & $\checkmark$ & & & & \\
\hline 35 & Hydroxycinnamic acid & Caffeic acid & $\mathrm{C} 9 \mathrm{H} 8 \mathrm{O} 4$ & 180.159 & 179 & $\mathbf{1 3 5}, 134,96$ & $324,299 \mathrm{sh}, 240$ & MS, NMR, DAD & $\checkmark$ & $\checkmark$ & $\checkmark$ & & \\
\hline 43 & Hydroxycinnamic acid & $p$-Coumaric acid & $\mathrm{C} 9 \mathrm{H} 8 \mathrm{O} 3$ & 164.160 & 163 & $119,104,93$ & $310,225,211,310 \mathrm{sh}$ & MS, NMR, DAD & $\checkmark$ & $\checkmark$ & $\checkmark$ & & \\
\hline 46 & Hydroxycinnamic acid & Ferulic acid & $\mathrm{C} 10 \mathrm{H} 10 \mathrm{O} 4$ & 194.186 & 193 & 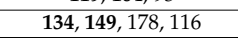 & $323,289,238 \mathrm{sh}$ & MS, NMR, DAD & $\checkmark$ & $\checkmark$ & $\checkmark$ & & \\
\hline 48 & Hydroxycinnamic acid & Sinapic acid & $\mathrm{C} 11 \mathrm{H} 12 \mathrm{O} 5$ & 224.212 & 223 & 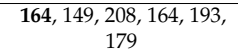 & 318,238 & MS & $\checkmark$ & & $\checkmark$ & & \\
\hline 83 & Hydroxycinnamic acid & Cinnamic acid & $\mathrm{C} 9 \mathrm{H} 8 \mathrm{O} 2$ & 148.161 & 147 & $103,77,87,129$ & $276,215,203$ & DAD & $\checkmark$ & & & & \\
\hline 3 & Flavan-3-ol & Gallocatechin & C15H14O7 & 306.270 & 305 & $\begin{array}{c}\mathbf{1 7 9}, \mathbf{2 2 1}, \mathbf{2 1 9}, 165,261, \\
125,137\end{array}$ & 274,370 & MS & $\checkmark$ & & & & \\
\hline 6 & Flavan-3-ol & Procyanidin B1 & $\mathrm{C} 30 \mathrm{H} 26 \mathrm{O} 12$ & 578.526 & 577 & $\begin{array}{c}425,407,289,451,287 \\
245,451\end{array}$ & 275,322 & MS, NMR, DAD & $\checkmark$ & $\checkmark$ & $\checkmark$ & & \\
\hline 10 & Flavan-3-ol & Procyanidin A1 & $\mathrm{C} 30 \mathrm{H} 24 \mathrm{O} 12$ & 576.501 & 575 & $\begin{array}{c}449,289,423,539,477 \\
407,441\end{array}$ & 280 & MS & $\checkmark$ & $\checkmark$ & $\checkmark$ & & \\
\hline 15 & Flavan-3-ol & Epigallocatechin & $\mathrm{C} 15 \mathrm{H} 14 \mathrm{O} 7$ & 306.270 & 305 & $\begin{array}{l}\mathbf{1 7 9 ,} \mathbf{1 6 5}, \mathbf{2 1 9}, \mathbf{2 2 1}, 261, \\
125,261,125\end{array}$ & $274,212,235$ & MS & $\checkmark$ & & & & \\
\hline 18 & Flavan-3-ol & Procyanidin $\mathrm{C} 1$ & $\mathrm{C} 45 \mathrm{H} 38 \mathrm{O} 18$ & 866.778 & 865 & $\begin{array}{c}695,407,577,287,713 \\
739,575,425,289\end{array}$ & 279 & MS, DAD & & $\checkmark$ & $\checkmark$ & & \\
\hline 19 & Flavan-3-ol & Procyanidin T2 & $\mathrm{C} 45 \mathrm{H} 38 \mathrm{O} 18$ & 866.778 & 865 & $\begin{array}{c}577,713,289,287,425 \\
575,695,407,739\end{array}$ & 280 & MS, DAD & & $\checkmark$ & $\checkmark$ & & \\
\hline 23 & Flavan-3-ol & Catechin & C15H14O6 & 290.271 & 289 & $\begin{array}{l}\mathbf{2 4 5}, \mathbf{2 0 3}, \mathbf{1 7 9}, 205,227 \\
\mathbf{1 0 9}, \mathbf{1 2 3}, 165,125,151\end{array}$ & 275,222 & MS, NMR, DAD & $\checkmark$ & $\checkmark$ & $\checkmark$ & & \\
\hline 25 & Flavan-3-ol & Procyanidin B3 & $\mathrm{C} 30 \mathrm{H} 26 \mathrm{O} 12$ & 578.526 & 577 & $\begin{array}{l}425,407,289,151,559, \\
445\end{array}$ & 270,330 & MS, NMR, DAD & $\checkmark$ & $\checkmark$ & & & \\
\hline 26 & Flavan-3-ol & Procyanidin B4 & $\mathrm{C} 30 \mathrm{H} 26 \mathrm{O} 12$ & 578.526 & 577 & $425,407,289$ & 280,240 & MS, DAD & $\checkmark$ & $\checkmark$ & & & \\
\hline
\end{tabular}


Table 1. Cont.

\begin{tabular}{|c|c|c|c|c|c|c|c|c|c|c|c|c|c|}
\hline ID $^{1}$ & Compound Group & $\begin{array}{l}\text { Compound } \\
\text { Name }^{1}\end{array}$ & $\begin{array}{l}\text { Chemical } \\
\text { Formula }^{2}\end{array}$ & $\begin{array}{c}\text { MW } \\
(\mathrm{g} / \mathrm{mol})\end{array}$ & {$[\mathrm{M}-\mathrm{H}]-$} & $\begin{array}{c}\text { Main MS/MS } \\
\text { Fragments }(\mathrm{m} / \mathrm{z})^{3,4}\end{array}$ & $\lambda \max \left(\mathrm{CH}_{3} \mathrm{OH}\right)(\mathrm{nm})$ & Detection Mode $^{5}$ & \multicolumn{5}{|c|}{ Tissue Distribution ${ }^{6}$} \\
\hline & & & & & & & & & LEAVES & STEMS & CANES & WOODS & ROOTS \\
\hline 29 & Flavan-3-ol & Procyanidin B2 & $\mathrm{C} 30 \mathrm{H} 26 \mathrm{O} 12$ & 578.526 & 577 & $\begin{array}{c}425,407,289,451,287, \\
245,125\end{array}$ & $280,240,370$ & MS, NMR, DAD & $\checkmark$ & $\checkmark$ & $\checkmark$ & & \\
\hline 37 & Flavan-3-ol & Epigallocatechin gallate & C22H18O11 & 458.375 & 457 & $\begin{array}{c}305,219,261,221,359, \\
169, \quad 305,289,271,125, \\
331\end{array}$ & 274,238 & MS, DAD & $\checkmark$ & & & & \\
\hline 38 & Flavan-3-ol & Prodelphinidin A-type & $\mathrm{C} 30 \mathrm{H} 26 \mathrm{O} 13$ & 594.527 & 593 & $\begin{array}{c}425,441,573,423,407, \\
289,531,273,339,245, \\
177,161 \\
\end{array}$ & $276,228,320$ & MS & & $\checkmark$ & $\checkmark$ & & \\
\hline 39 & Flavan-3-ol & Procyanidin dimer gallate & NA & NA & 729 & $\begin{array}{l}577,407,559,451,711, \\
289,593,437,425\end{array}$ & 280 & MS, DAD & & $\checkmark$ & $\checkmark$ & & \\
\hline 40 & Flavan-3-ol & Epicatechin & $\mathrm{C} 15 \mathrm{H} 14 \mathrm{O} 6$ & 290.271 & 289 & $\begin{array}{c}245,203,109,179,205 \\
123,125,151\end{array}$ & 277,226 & MS, NMR, DAD & $\checkmark$ & $\checkmark$ & $\checkmark$ & & \\
\hline 42 & Flavan-3-ol & Gallocatechin gallate & C22H18O11 & 458.375 & 457 & $\begin{array}{c}169,161,359,331,169 \\
305,193\end{array}$ & 276,240 & MS & $\checkmark$ & & & & \\
\hline 47 & Flavan-3-ol & Epicatechin gallate & $\mathrm{C} 22 \mathrm{H} 18 \mathrm{O} 10$ & 442.376 & 441 & $\begin{array}{c}289,245,205,169,125 \\
331,271,179\end{array}$ & 278,240 & MS, NMR, DAD & $\checkmark$ & $\checkmark$ & & & \\
\hline 61 & Flavan-3-ol & Catechin gallate & $\mathrm{C} 22 \mathrm{H} 18 \mathrm{O} 10$ & 442.376 & 441 & 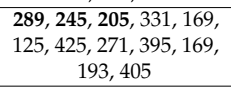 & 278 & MS & $\checkmark$ & $\checkmark$ & & & \\
\hline 33 & Anthocyanin & Delphinidin-3-O-glucoside & C21H21O12+ & 465.387 & 463 & $301,300,271,125$ & $526,361,277,402 \mathrm{sh}$ & DAD & $\checkmark$ & & & & \\
\hline 34 & Anthocyanin & Cyanidin-3-O-glucoside & C21H21O11+ & 449.388 & 447 & $\begin{array}{l}\mathbf{2 8 4}, \mathbf{2 1 1}, 285,255,147, \\
227\end{array}$ & $516,262,301 \mathrm{sh}$ & MS, DAD & $\checkmark$ & & & & \\
\hline 44 & Anthocyanin & Petunidin-3-O-glucoside & $\mathrm{C} 22 \mathrm{H} 23 \mathrm{O} 12+$ & 479.414 & 477 & $314,315,299,300$ & $526,344 \mathrm{sh}, 277$ & DAD & $\checkmark$ & & & & \\
\hline 45 & Anthocyanin & Peonidin-3-O-glucoside & $\mathrm{C} 22 \mathrm{H} 23 \mathrm{O} 11+$ & 463.415 & 461 & $\begin{array}{l}299,298,284,255,227, \\
211\end{array}$ & $517,280,330$ sh, 421 sh & MS, DAD & $\checkmark$ & & & & \\
\hline 52 & Anthocyanin & Malvidin-3-O-glucoside & $\mathrm{C} 23 \mathrm{H} 25 \mathrm{O} 12+$ & 493.441 & 491 & $329,314,299$ & $528,348 \mathrm{sh}, 288$ & MS, DAD & $\checkmark$ & $\checkmark$ & & & \\
\hline 59 & Anthocyanin & Petunidin-3-(6-O-acetyl)glucoside & C24H25O13+ & 521.451 & 519 & $315,302,274,149$ & $528,270,350$ sh & DAD & $\checkmark$ & & & & \\
\hline 62 & Anthocyanin & Peonidin-3-(6-O-acetyl)glucoside & $\mathrm{C} 24 \mathrm{H} 25 \mathrm{O} 12+$ & 505.452 & 504 & $301,286,230,258,268$ & 522,280 & DAD & $\checkmark$ & & & & \\
\hline 67 & Anthocyanin & Malvidin-3-(6-O-acetyl)glucoside & C25H27O13+ & 535.478 & 533 & 329,315 & $522,344,278$ & DAD & $\checkmark$ & & & & \\
\hline 72 & Anthocyanin & Cyanidin-3-(6-O-coumaroyl)glucoside & C30H27O13+ & 595.533 & 593 & $287,259,231,213,259$ & $524,314,284,449 \mathrm{sh}$ & DAD & $\checkmark$ & & & & \\
\hline 80 & Anthocyanin & Petunidin-3-(6-O-coumaroyl)glucoside & C31H29O14+ & 625.553 & 624 & $\begin{array}{l}317,302,274,218,228, \\
246\end{array}$ & $534,282,313$ & DAD & $\checkmark$ & & & & \\
\hline 81 & Anthocyanin & Peonidin-3-(6-O-coumaroyl)glucoside & C31H29O13+ & 609.554 & 608 & $301,286,230,258,268$ & 522,312 & MS, DAD & $\checkmark$ & & & & \\
\hline 85 & Anthocyanin & Malvidin-3-(6-O-coumaroyl)glucoside & $\mathrm{C} 32 \mathrm{H} 31 \mathrm{O} 14+$ & 639.586 & 637 & $329,299,281$ & 534,318 & DAD & $\checkmark$ & & & & \\
\hline 86 & Anthocyanin & Malvidin-3-(6-O-caffeoyl)glucoside & $\mathrm{C} 32 \mathrm{H} 31 \mathrm{O} 15+$ & 655.581 & 655 & $331,299,637,315,475$ & $532,324,284$ & MS & & $\checkmark$ & & & \\
\hline 87 & Anthocyanin & Malvidin-3-O-rutinoside & $\mathrm{C} 29 \mathrm{H} 35 \mathrm{O} 16+$ & 639.583 & 637 & 331 & 526,288 & MS & & $\checkmark$ & & & \\
\hline 41 & Flavanone & Taxifolin & $\mathrm{C} 15 \mathrm{H} 12 \mathrm{O} 7$ & 304.254 & 303 & $\begin{array}{c}\mathbf{2 8 5}, \mathbf{1 2 5}, \mathbf{1 7 7}, 275,151, \\
259,217\end{array}$ & $290,326 \mathrm{sh}$ & MS & $\checkmark$ & & & & \\
\hline 55 & Flavanone & Taxifolin-O-pentoside & $\mathrm{C} 20 \mathrm{H} 20 \mathrm{O} 11$ & 436.371 & 435 & $\begin{array}{c}303,285,399,151,241 \\
217,175\end{array}$ & 274,317 & MS & & $\checkmark$ & & & \\
\hline 56 & Flavanone & Taxifolin-3-O-glucoside & $\mathrm{C} 21 \mathrm{H} 22 \mathrm{O} 12$ & 466.395 & 465 & $\begin{array}{c}285,303,151,339,177, \\
259,447\end{array}$ & 290 & MS & & $\checkmark$ & & & \\
\hline 57 & Flavanone & Taxifolin-3-O-rhamnoside & C21H22O11 & 450.396 & 449 & $303,285,151,323,431$ & 292,235 & MS & & $\checkmark$ & & & \\
\hline 88 & Flavanone & Hesperetin & $\mathrm{C} 16 \mathrm{H} 14 \mathrm{O} 6$ & 302.282 & 301 & $258,143,157,137,286$ & $284,324 \mathrm{sh}, 221$ & MS & $\checkmark$ & & & & \\
\hline 95 & Flavanone & Eriodictyol-7-O-glucoside & $\mathrm{C} 21 \mathrm{H} 22 \mathrm{O} 11$ & 450.396 & 449 & $\begin{array}{l}\mathbf{2 8 7 ,}, \mathbf{2 6 9}, \mathbf{1 5 1}, 135,259, \\
225,209,431\end{array}$ & 281,327 & MS & $\checkmark$ & & & & \\
\hline 103 & Flavanone & Naringenin & C15H12O5 & 272.256 & 271 & $\begin{array}{c}151,177,119,165,125 \\
107,227,191\end{array}$ & $289,228,336 \mathrm{sh}$ & MS & $\checkmark$ & & & & \\
\hline 104 & Flavanone & Naringenin-7-O-glucoside & $\mathrm{C} 21 \mathrm{H} 22 \mathrm{O} 10$ & 434.397 & 433 & $\begin{array}{c}271,269,313,177,151 \\
119,107\end{array}$ & 282,222 & MS & $\checkmark$ & & & & \\
\hline
\end{tabular}


Table 1. Cont.

\begin{tabular}{|c|c|c|c|c|c|c|c|c|c|c|c|c|c|}
\hline ID $^{1}$ & Compound Group & $\begin{array}{c}\text { Compound } \\
\text { Name }^{1}\end{array}$ & $\begin{array}{l}\text { Chemical } \\
\text { Formula }^{2}\end{array}$ & $\begin{array}{c}\mathrm{MW} \\
(\mathrm{g} / \mathrm{mol})\end{array}$ & {$[\mathrm{M}-\mathrm{H}]-$} & $\begin{array}{c}\text { Main MS/MS } \\
\text { Fragments }\left(\mathrm{m} / \mathbf{z}^{3,4}\right.\end{array}$ & $\lambda \max \left(\mathrm{CH}_{3} \mathrm{OH}\right)(\mathrm{nm})$ & Detection Mode 5 & \multicolumn{5}{|c|}{ Tissue Distribution ${ }^{6}$} \\
\hline & & & & & & & & & LEAVES & STEMS & CANES & WOODS & ROOTS \\
\hline 49 & Flavonol & Myricetin-3-O-galactoside & $\mathrm{C} 21 \mathrm{H} 20 \mathrm{O} 13$ & 480.378 & 479 & $317,316,178,271$ & 360,265 & MS, DAD & $\checkmark$ & & & & \\
\hline 51 & Flavonol & Myricetin-3-O-glucuronide & $\mathrm{C} 21 \mathrm{H} 18 \mathrm{O} 14$ & 494.361 & 493 & 317 & $353,300 \mathrm{sh}, 261$ & MS, DAD & $\checkmark$ & & & & \\
\hline 53 & Flavonol & Myricetin-3-O-glucoside & $\mathrm{C} 21 \mathrm{H} 20 \mathrm{O} 13$ & 480.378 & 479 & $\begin{array}{c}317,316,169,271,303, \\
227,179,151\end{array}$ & $362,298 \mathrm{sh}, 260$ & MS, DAD & $\checkmark$ & & & & \\
\hline 54 & Flavonol & Quercetin-3-O-rutinoside & $\mathrm{C} 27 \mathrm{H} 30 \mathrm{O} 16$ & 610.521 & 609 & $\begin{array}{c}301,300,271,255,179 \\
343,151\end{array}$ & $353,256,294 \mathrm{sh}$ & MS, NMR, DAD & $\checkmark$ & $\checkmark$ & & & \\
\hline 58 & Flavonol & Quercetin-3-O-galactoside & $\mathrm{C} 21 \mathrm{H} 20 \mathrm{O} 12$ & 464.379 & 463 & $\begin{array}{l}\mathbf{3 0 1}, \mathbf{3 0 0}, 179,273,257, \\
151\end{array}$ & $362,256,301 \mathrm{sh}$ & MS, NMR, DAD & $\checkmark$ & $\checkmark$ & $\checkmark$ & & \\
\hline 60 & Flavonol & Quercetin-3-O-glucoside & $\mathrm{C} 21 \mathrm{H} 20 \mathrm{O} 12$ & 464.379 & 463 & $\begin{array}{c}3 \mathbf{3 0 1}, \mathbf{3 0 0}, \mathbf{2 7 1}, 161,179 \\
255,151\end{array}$ & $358,256,300$ sh & MS, NMR, DAD & $\checkmark$ & $\checkmark$ & & & \\
\hline 63 & Flavonol & Quercetin-3-O-glucuronide & $\mathrm{C} 21 \mathrm{H} 18 \mathrm{O} 13$ & 478.362 & 477 & $\begin{array}{c}\text { 301, 179, } 151,283,459, \\
431,501\end{array}$ & $356,254,300$ sh & MS, NMR, DAD & $\checkmark$ & $\checkmark$ & & & \\
\hline 65 & Flavonol & Myricetin-3-O-rhamnoside & $\mathrm{C} 21 \mathrm{H} 20 \mathrm{O} 12$ & 464.379 & 463 & $\begin{array}{c}317,316,271,300,179, \\
287,151\end{array}$ & $372,302 \mathrm{sh}, 248$ & MS & $\checkmark$ & & & & \\
\hline 68 & Flavonol & Myricetin & $\mathrm{C} 15 \mathrm{H} 10 \mathrm{O} 8$ & 318.237 & 317 & $\begin{array}{c}\mathbf{1 5 1}, \mathbf{1 7 9}, 137,287,271, \\
109,192\end{array}$ & $372,253,303 \mathrm{sh}, 207$ & MS, NMR, DAD & $\checkmark$ & & & & \\
\hline 69 & Flavonol & Quercetin-3-O-rhamnoside & C21H20O11 & 448.380 & 447 & $\begin{array}{l}301,300,179,151,271, \\
257\end{array}$ & $354,258,307 \mathrm{sh}$ & $\mathrm{MS}$, NMR, DAD & $\checkmark$ & $\checkmark$ & & & \\
\hline 70 & Flavonol & Kaempferol-3-O-galactoside & C21H20O11 & 448.380 & 447 & $285,255,227,327$ & 361,260 & MS & $\checkmark$ & & & & \\
\hline 71 & Flavonol & Kaempferol-3-O-rutinoside & C27H30O15 & 594.522 & 593 & $\begin{array}{l}285,257,151,447,199, \\
241,93\end{array}$ & 354,274 & MS, DAD & $\checkmark$ & $\checkmark$ & & & \\
\hline 73 & Flavonol & Kaempferol-3-O-glucuronide & $\mathrm{C} 21 \mathrm{H} 18 \mathrm{O} 12$ & 462.363 & 461 & $\begin{array}{l}285,267,443,417,257, \\
229\end{array}$ & 348,265 & MS, DAD & $\checkmark$ & & & & \\
\hline 74 & Flavonol & Quercetin-3-(6-O-acetyl)glucoside & $\mathrm{C} 23 \mathrm{H} 22 \mathrm{O} 13$ & 506.416 & 505 & $301,300,463,271,255$ & $354,256,267 \mathrm{sh}, 298 \mathrm{sh}$ & MS & $\checkmark$ & & & & \\
\hline 75 & Flavonol & Quercetin-3-(3-O-arabinosyl)glucoside & $\mathrm{C} 26 \mathrm{H} 28 \mathrm{O} 16$ & 596.493 & 595 & $\begin{array}{l}301,517,151,300,463, \\
179,445,271,255\end{array}$ & $354,260,231$ & MS & $\checkmark$ & & & & \\
\hline 76 & Flavonol & Quercetin-3-(7-O-glucosyl)glucuronide & C27H28018 & 640.503 & 639 & $477,301,179,151$ & $361,300,268,256$ & DAD & $\checkmark$ & & & & \\
\hline 77 & Flavonol & Quercetin-3-O-arabinose & C20H18O11 & 434.350 & 433 & $\mathbf{3 0 1}, \mathbf{1 7 9}, 151,300,283$ & 358,311 & MS & & $\checkmark$ & $\checkmark$ & & \\
\hline 78 & Flavonol & & $\mathrm{C} 33 \mathrm{H} 40 \mathrm{O} 21$ & 772.662 & 771 & 609,301 & $355,259,299 \mathrm{sh}, 204$ & NMR, DAD & $\checkmark$ & & & & \\
\hline 79 & Flavonol & Kaempferol-3-O-glucoside & $\mathrm{C} 21 \mathrm{H} 20 \mathrm{O} 11$ & 448.380 & 447 & $\begin{array}{l}285,255,151,227,327, \\
243\end{array}$ & $348,263,297 \mathrm{sh}$ & MS, DAD & $\checkmark$ & $\checkmark$ & & & \\
\hline 82 & Flavonol & Quercetin & $\mathrm{C} 15 \mathrm{H} 10 \mathrm{O} 7$ & 302.239 & 301 & $\begin{array}{c}151,179,273,193,257 \\
229\end{array}$ & $372,255,202 \mathrm{sh}, 300 \mathrm{sh}$ & MS, NMR, DAD & $\checkmark$ & $\checkmark$ & & & \\
\hline 84 & Flavonol & Kaempferol & C15H10O6 & 286.239 & 285 & $\begin{array}{c}187, \mathbf{1 1 7}, \mathbf{2 1 1}, 127,257, \\
151,169,241\end{array}$ & $369,258,390$ & MS, NMR, DAD & $\checkmark$ & $\checkmark$ & & & \\
\hline 89 & Flavonol & Kaempferol-3-O-xyloside & $\mathrm{C} 20 \mathrm{H} 18 \mathrm{O} 10$ & 418.354 & 417 & $285,255,227$ & 350 & MS & $\checkmark$ & & & & \\
\hline 90 & Flavonol & Kaempferol-3-O-rhamnoside & $\mathrm{C} 21 \mathrm{H} 20 \mathrm{O} 10$ & 432.381 & 431 & 285 & $351,264,202,294 \mathrm{sh}$ & MS & $\checkmark$ & & & & \\
\hline 91 & Flavonol & Dihydrokaempferol-3-O-rhamnoside & $\mathrm{C} 21 \mathrm{H} 22 \mathrm{O} 10$ & 434.397 & 433 & $\begin{array}{l}269,287,259,180,151, \\
368\end{array}$ & 286,230 & MS & & $\checkmark$ & & & \\
\hline 92 & Flavonol & Isorhamnetin-3-O-galactoside & $\mathrm{C} 22 \mathrm{H} 22 \mathrm{O} 12$ & 478.406 & 477 & $315,314271,300,357$ & $366,289,259$ & MS & $\checkmark$ & & & & \\
\hline 93 & Flavonol & Isorhamnetin-3-O-glucoside & $\mathrm{C} 22 \mathrm{H} 22 \mathrm{O} 12$ & 478.406 & 477 & $315,314,285,357,271$ & $354,265 \mathrm{sh}$ & MS, DAD & $\checkmark$ & & & & \\
\hline 94 & Flavonol & Quercetin-3-(6-O-rhamnosyl)galactoside & $\mathrm{C} 27 \mathrm{H} 30 \mathrm{O} 16$ & 610.517 & 609 & $\begin{array}{c}\mathbf{3 0 1}, \mathbf{5 4 1}, \mathbf{4 6 3}, 300,271, \\
\quad 255,179,447,151\end{array}$ & $356,256,300$ & NMR, DAD & $\checkmark$ & & & & \\
\hline 96 & Flavonol & Isorhamnetin-3-O-arabinose & $\mathrm{C} 21 \mathrm{H} 20 \mathrm{O} 11$ & 448.381 & 447 & $315,314,271,243$ & 345,258 & MS & $\checkmark$ & & & & \\
\hline 97 & Flavonol & Isorhamnetin-3-O-glucuronide & $\mathrm{C} 22 \mathrm{H} 20 \mathrm{O} 13$ & $\begin{aligned} 4+0.001 \\
492.389\end{aligned}$ & 491 & $315,255,151$ & $355,265 \mathrm{sh}$ & MS & 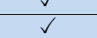 & & & & \\
\hline 98 & Flavonol & Isorhamnetin-3-O-rutinoside & $\mathrm{C} 28 \mathrm{H} 32 \mathrm{O} 16$ & 624.548 & 623 & $315,300,468$ & 354,256 & MS & 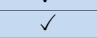 & & & & \\
\hline 99 & Flavonol & Isorhamnetin-3-(6-O-feruloyl)glucoside & $\mathrm{C} 32 \mathrm{H} 30 \mathrm{O} 15$ & 654.577 & 653 & 315 & 320,274 & MS & & $\checkmark$ & & & \\
\hline 100 & Flavonol & Isorhamnetin-3-(4-O-rhamnosyl)rutinoside & $\mathrm{C} 34 \mathrm{H} 42 \mathrm{O} 20$ & 770.685 & 769 & $461,623,163$ & 354,256 & MS, DAD & $\checkmark$ & & & & \\
\hline 101 & Flavonol & Kaempferol-3-(6-O-coumaroyl)glucoside & $\mathrm{C} 30 \mathrm{H} 26 \mathrm{O} 13$ & 594.525 & 593 & $285,227,255$ & $317,265,356 \mathrm{sh}, 310 \mathrm{sh}$ & MS & $\checkmark$ & & & & \\
\hline
\end{tabular}


Table 1. Cont.

\begin{tabular}{|c|c|c|c|c|c|c|c|c|c|c|c|c|c|}
\hline ID $^{1}$ & Compound Group & $\begin{array}{l}\text { Compound } \\
\text { Name }^{1}\end{array}$ & $\begin{array}{l}\text { Chemical } \\
\text { Formula }^{2}\end{array}$ & $\begin{array}{c}\text { MW } \\
(\mathrm{g} / \mathrm{mol})\end{array}$ & {$[\mathrm{M}-\mathrm{H}]-$} & $\begin{array}{c}\text { Main MS/MS } \\
\text { Fragments }\left(\mathrm{m} / \mathbf{z}^{3,4}\right.\end{array}$ & $\lambda \max \left(\mathrm{CH}_{3} \mathrm{OH}\right)(\mathrm{nm})$ & Detection Mode ${ }^{5}$ & \multicolumn{5}{|c|}{ Tissue Distribution ${ }^{6}$} \\
\hline & & & & & & & & & LEAVES & STEMS & CANES & WOODS & ROOTS \\
\hline 102 & Flavonol & Kaempferol-3 (7-O-glucosyl)galactoside & C27H30O16 & 610.521 & 609 & $447,489,285$ & $343,300 \mathrm{sh}, 265$ & DAD & $\checkmark$ & & & & \\
\hline 105 & Flavonol & Diquercetin-3-(3-O-glucosyl)glucuronide & $\mathrm{C} 42 \mathrm{H} 36 \mathrm{O} 24$ & 924.722 & 923 & $\begin{array}{c}765,755,837,903,935, \\
808\end{array}$ & 374 & MS & $\checkmark$ & & & & \\
\hline 64 & Flavone & Apigenin-7-O-glucoside & $\mathrm{C} 21 \mathrm{H} 20 \mathrm{O} 10$ & 432.381 & 431 & $\begin{array}{c}269,283,311,413,231 \\
225,201,197,149\end{array}$ & $335,269,253$ & MS, NMR, DAD & $\checkmark$ & & & & \\
\hline 66 & Flavone & Luteolin-7-O-glucoside & $\mathrm{C} 21 \mathrm{H} 20 \mathrm{O} 11$ & 448.380 & 447 & $\begin{array}{l}285,226,257,217,241, \\
198\end{array}$ & $349,254 \mathrm{sh}, 205$ & MS, NMR, DAD & $\checkmark$ & & & & \\
\hline 5 & Coumarin & Aesculin & C15H16O9 & 340.282 & 339 & $\mathbf{1 3 3}, 177,150$ & 346,289 & MS & $\checkmark$ & & & & \\
\hline 11 & Dihydrochalcone & Phlorizin & $\mathrm{C} 21 \mathrm{H} 24 \mathrm{O} 10$ & 436.413 & 435 & $273,167,229,297$ & $285,230 \mathrm{sh}$ & MS & $\checkmark$ & & & & \\
\hline 12 & Coumarin & Fraxin & $\mathrm{C} 16 \mathrm{H} 18 \mathrm{O} 10$ & 370.310 & 369 & $207,192,354,149,123$ & $332,308 \mathrm{sh}$ & MS & $\checkmark$ & & & & \\
\hline 13 & Coumarin & Aesculetin & $\mathrm{C} 9 \mathrm{H} 6 \mathrm{O} 4$ & 178.143 & 177 & $\begin{array}{c}\mathbf{1 4 9}, \mathbf{1 3 3}, 105,91,115,89, \\
65\end{array}$ & $334,288 \mathrm{sh}$ & MS & $\checkmark$ & & & & \\
\hline 17 & Coumarin & Umbelliferone & $\mathrm{C} 9 \mathrm{H} 6 \mathrm{O} 3$ & 162.144 & 161 & $\mathbf{1 3 3}, 117,105,51,78$ & 323,236 & MS & $\checkmark$ & & & & \\
\hline
\end{tabular}

${ }^{1}$ Other reported names are found in Table S1, where compounds are numbered (ID) according to their elution patterns. ${ }^{2} \mathrm{NA}=$ not available or not applicable, MW = Molecular Weight. ${ }^{3}$ MS-MS values in italic (compounds $62,72,80,81$ ) are reported in positive mode. ${ }^{4}$ The most abundant fragments are highlighted in bold. ${ }^{5}$ MS $=$ mass spectrometry detection, $\mathrm{NMR}=$ nuclear magnetic resonance detection, $\mathrm{DAD}=$ diode array or ultraviolet detection. ${ }^{6}$ In blue with $\sqrt{ }$ are detected compounds; in light red are undetected compounds or unavailable information. 


\subsection{Flavan-3-Ols or Flavanols}

The condensation of three C2 residues with an activated hydroxycinnamic acid produces metabolites with a second aromatic ring linked to the phenylpropanoid moiety, with a common C6-C3-C6 skeleton of flavonoids. The basic flavonoid chemical structure is the flavan nucleus, consisting of 15 carbon atoms arranged in two benzene rings (A and B) linked via a heterocyclic oxygen-containing pyran ring (C). The main classes of flavonoids differ in the level of oxidation and saturation of the $\mathrm{C}$ ring, the most relevant being flavan-3-ols including proanthocyanidins, anthocyanins, flavanones, flavonols, and flavones [35,65]. Flavan-3-ols exhibit a saturated C-ring hydroxylated in the 3-position. The A-ring of flavan-3-ols is generally hydroxylated in C5 and C7 and the B-ring in C4. Diversity arises from the substitution pattern of the B-ring and can be increased by galloylation and glucosylation of the 3-hydroxyl group [76]. The presence of two asymmetric carbons (in C2 and C3) opens the possibility for different stereoisomers, that is, $2 R, 3 S$ (2,3-trans), $2 R, 3 R(2,3-$ cis $), 2 S, 3 R$ (2,3-trans), and $2 S, 3 S$ (2,3-cis) configurations. The following eight flavanol monomers are reported in grapevine leaves, stems, and canes: catechin, gallocatechin, epigallocatechin, epigallocatechin gallate, epicatechin, gallocatechin gallate, epicatechin gallate, and catechin gallate (Table 1) [32,59,69,73,77].

\subsection{Proanthocyanidins}

Proanthocyanidins, also known as condensed tannins, are both oligomeric and polymeric compounds arising from flavanol condensation. Linkages between constitutive flavan-3-ol units are found between $\mathrm{C} 4$ and $\mathrm{C} 6$ or $\mathrm{C} 4$ and $\mathrm{C} 8$ in the case of B-type proanthocyanidins. A-type are linked with additional $\mathrm{C} 2-\mathrm{O}-\mathrm{C} 7$ or $\mathrm{C} 2-\mathrm{O}-\mathrm{C} 5$ bonds. Substitution in the 4-position gives rise to another asymmetric center on extension and upper units, but the usual configuration is 3,4-trans (i.e., $3 S, 4 S$ or $3 R, 4 S$ ). The chain length of one polymer is described by the degree of polymerization (DP), and the mean degree of polymerization (mDP) of a heterogeneous population of polymers [76]. The following nine proanthocyanidins are reported in grapevine leaves, stems, and canes: procyanidin A1, procyanidin $\mathrm{B} 1$, procyanidin $\mathrm{B} 2$, procyanidin B3, procyanidin B4, procyanidin $\mathrm{C}$, procyanidin $\mathrm{T} 2$, prodelphinidin A-type (reported as epigallocatechin-epicatechin dimer by some authors), and a procyanidin dimer gallate (Table 1) $[33,50,53,69,76,77]$.

\subsection{Anthocyanins}

Anthocyanins share the same molecular structure of flavonoids composed by one heterocyclic benzopyran ring (as the $C$ ring), one fused aromatic ring (as the A ring), and one phenyl constituent (as the B ring). Nevertheless, they differ on the basis of hydroxyl or methoxyl substitutions in the lateral phenyl B ring, and, in general, for glycosylations and esterifications. Anthocyanins of Vitis are structurally based on five aglycones/anthocyanidins-malvidin, cyanidin, delphinidin, peonidin, and petunidin-which differentiate on the basis of number and position of their hydroxyl groups and their degree of methylation. Acylation occurs at the C6 position of the glucose molecule by esterification with acetic, $p$-coumaric, and caffeic acids [77,78]. Anthocyanins have been mainly reported in the leaves of grapevine (at least 14) and include: delphinidin-3-O-glucoside, cyanidin-3-O-glucoside, cyanidin-3-(6-O-coumaroyl)glucoside, petunidin-3-O-glucoside, petunidin-3-(6-O-acetyl)glucoside, petunidin-3-(6-O-coumaroyl)glucoside, peonidin-3-O-glucoside, peonidin-3-(6-O-acetyl)glucoside, peonidin-3-(6-O-coumaroyl)glucoside, malvidin-3-O-glucoside, malvidin-3-(6-O-acetyl)glucoside, malvidin-3-(6-O-coumaroyl)glucoside, malvidin-3-(6-O-caffeoyl)glucoside, and malvidin-3-O-rutinoside (Table 1) [4,5,77-79].

\subsection{Flavones}

Flavones are the simplest members of the class of flavonoids and consist of $4 \mathrm{H}$-chromen-4-one bearing a phenyl substituent at position 2 [65]. Among the flavonoids naturally occurring in grapevine, 
flavones represent the least common group of aromatic compounds with only apigenin-7-O-glucoside and luteolin-7-O-glucoside reported in the leaves (Table 1) [4].

\subsection{Flavonols}

Chemically, flavonols or 3-hydroxyflavones differ from many other flavonoids in that they have a double bond between positions 2 and 3 and an oxygen (a ketone group) in position 4 of the $C$ ring, like flavones; however, they differ from flavones due to the presence of a hydroxyl group at the position 3. Most of the flavonols exist as $\mathrm{O}$-glycosides and seldomly as $\mathrm{C}$-glycosides, and their conjugated derivatives (glycones) are mainly bound to sugars, hydroxycinnamic acids, or organic acids [35]. Flavonols make up the largest group of flavonoid compounds encountered in grapevine leaves and stems, with at least 35 compounds reported in the literature (Table 1) $[1,2,4,5,32,34,59,66,77,79,80]$ derived from four aglycones: myricetin, quercetin, kaempferol, and isorhamnetin:

- Myricetin, myricetin-3-O-galactoside, myricetin-3-O-glucuronide, myricetin-3-O-glucoside, and myricetin-3-O-rhamnoside;

- Quercetin, quercetin-3-O-rutinoside, quercetin-3-O-galactoside, quercetin-3-O-glucoside, quercetin-3$O$-glucuronide, quercetin-3-O-rhamnoside, quercetin-3-(6-O-acetyl)glucoside, quercetin-3(3-O-arabinosyl)glucoside, quercetin-3-(7-O-glucosyl)glucuronide, quercetin-3-O-arabinose (reported as quercetin-O-pentoside by some authors), quercetin-3-(3-O-rhamnosyl)glucoside-7-O-rhamnoside, quercetin-3-(6-O-rhamnosyl)galactoside, and diquercetin-3-(3-O-glucosyl)glucuronide;

- Kaempferol, kaempferol-3-O-galactoside, kaempferol-3-O-rutinoside, kaempferol-3-O-glucuronide, kaempferol-3-O-glucoside, kaempferol-3-O-xyloside (or kaempferol-O-pentoside by some authors), kaempferol-3- O-rhamnoside, dihydrokaempferol-3-O-rhamnoside, kaempferol-3-(6-O-coumaroyl) glucoside, and kaempferol-3-(7-O-glucosyl)galactoside (or kaempferol-3,7-diglucoside by some authors);

- Isorhamnetin-3-O-galactoside, isorhamnetin-3-O-glucoside, isorhamnetin-3-O-arabinose (or isorhamnetin-O-pentoside by some authors), isorhamnetin-3-O-glucuronide, isorhamnetin-3O-rutinoside, isorhamnetin-3-(6-O-feruloyl)glucoside, and isorhamnetin-3-(4-O-rhamnosyl)rutinoside (or isorhamnetin diglycoside by some authors).

\subsection{Flavanones}

Flavanones (also called 2,3-dihydroxyflavones) lack the double bond between carbons 2 and 3 in the C-ring of the flavonoid skeleton, which is present in flavones and flavonols. Thus, flavanones are chiral at the $\mathrm{C} 2$ position, and are generally glycosylated by glucoside or disaccharide at position seven to give flavanone glycosides [65]. The following eight flavanones have been reported in the vine plant: taxifolin, taxifolin-O-pentoside, taxifolin-3-O-glucoside, taxifolin-3-O-rhamnoside, hesperetin, eriodictyol-7-O-glucoside, naringenin, and naringenin-7-O-glucoside (Table 1) [4,74].

\subsection{Coumarins and Dihydrochalcones}

Coumarins are 1,2-benzopyrones (fused benzene and $\alpha$-pyrone rings) that are derived from the phenylpropanoid pathway, but can also be produced through the cleavage of $O$-hydroxycinnamic acid that exist in free or glycosylated forms. In studies aimed at identifying polyphenols in grapevine, the following compounds have been detected: aesculin, fraxin, aesculetin, umbelliferone (coumarins), and phlorizin (dihydrochalcone) (Table 1) [19,32,81,82].

\subsection{Non-Phenolic Compounds}

The literature surveyed reveals that at least eight non-phenolic compounds or volatile compounds are usually eluted with phenolic compounds, and these include pyrogallol and catechol (benzenediols), sinapaldehyde, syringaldehyde and coniferaldehyde (hydroxycinnamaldehydes), vanillin and acetovanillone (benzaldehydes), and arbutin (hydroquinone) (Table S1) [35,46,47,55,60,83]. Moreover, 
some still unknown compounds with phenolic characteristics have been reported, and their importance can be estimated only if their chemical structure is determined.

\section{Stilbenic Compounds Identified in the Vegetative Organs of Grapevine}

The condensation of three $\mathrm{C} 2$ residues with an activated hydroxycinnamic acid (as with flavonoids) produces stilbenes, which are metabolites with an essential structural skeleton of two aromatic rings joined by an ethylene bridge (C6-C2-C6) [31,50]. Stilbenes emit a blue fluorescence under UV light with excitation and emission peaks around 320 and $390 \mathrm{~nm}$, respectively [52,63]; in fact, the name "stilbene" derives from the Greek word "stilbos", which is translated as "shining" [16,36]. The chemical structure of stilbenes in both the monomeric and oligomeric states is constituted by a diphenylethylene group oriented in trans or cis. The presence of a cis-stilbenic chromophore gives rise to different spectra, with an absorption maximum of lower intensity and of shorter wavelength compared with that of the trans-isomer [61]. Light exposition of trans-stilbene solutions has been shown to partially photoisomerize stilbenes into $c$ is forms $[7,59,61]$. There are several areas of confusion with stilbene nomenclature. According to current practice however, the trans/cis nomenclature is used to describe the stereochemistry at saturated rings, whereas the Z/E nomenclature is used to describe the stereochemistry of double bonds $[8,13,61,64]$. In this review, the trans/cis nomenclature is used, although at least two compounds have been reported with other nomenclatures, namely, miyabenol $C$ and $\varepsilon$-viniferin. Both trans-E-miyabenol $C$ and trans-Z-miyabenol $C$ are reported in the literature [61]. In the case of $\varepsilon$-viniferin, there are two stereochemical centers, at positions $7 \mathrm{a}$ and $8 \mathrm{a}$ on the dihydrofuran ring, allowing for four potential stereoisomers: (+)-trans- $\varepsilon$-viniferin, (-)-trans- $\varepsilon$-viniferin), (+)-cis- $\varepsilon$-viniferin,

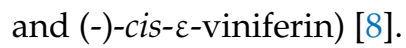

Most stilbenes have been identified using NMR and MS, which are the most informative techniques. Using MS, the initial identification of compounds is performed on the exact mass measurement of the monoisotopic ion and isotopic pattern, enabling the molecular formula to be identified with a high-confidence score and low mass error. Exact mass measurements of MS/MS fragments either confirm or deny the putative structure. Because MS/MS cannot distinguish between isomeric compounds, tentative assignment is also based on comparisons with data found in the literature $[13,16]$ and NMR profiles. In addition, UV-VIS data based on $\lambda$ max and UV spectrum when available are compared with those in the literature [12,61]. With this approach, a total of 78 stilbenes have been successfully identified in the vegetative tissues of the vine plant. A database of these stilbenes is provided in Table 2; the masses, when available, are those derived from the negative ion LC-MS datasets. Mass data are usually in agreement among publications, with minor changes in product ions owing to different fragmentation conditions. 
Table 2. Stilbenic compounds in the vegetative organs of the grapevine plant.

\begin{tabular}{|c|c|c|c|c|c|c|c|c|c|c|c|c|c|}
\hline ID $^{1}$ & $\begin{array}{l}\text { Compound } \\
\text { Group }\end{array}$ & Compound Name 1,2 & $\begin{array}{l}\text { Chemical } \\
\text { Formula }^{3}\end{array}$ & $\underset{(\mathrm{g} / \mathrm{mol})}{\mathrm{MW}}$ & $\begin{array}{l}{[\mathrm{M}-\mathrm{H}]-} \\
\text { Precursor }\end{array}$ & $\begin{array}{c}\text { Main MS/MS } \\
\text { Fragments (m/z) }{ }^{4}\end{array}$ & $\underset{(\mathrm{mm})}{\lambda \max \left(\mathrm{CH}_{3} \mathrm{OH}\right)}$ & Detection Mode ${ }^{5}$ & \multicolumn{5}{|c|}{ Tissue Distribution ${ }^{6}$} \\
\hline & & & & & & & & & LEAVES & STEMS & CANES & WOODS & ROOTS \\
\hline 106 & Monomers & trans-Astringin & $\mathrm{C} 20 \mathrm{H} 22 \mathrm{O} 9$ & 406.383 & 405 & $\begin{array}{c}243,225,201,322,159, \\
199,173\end{array}$ & 331,305 & MS & $\checkmark$ & $\checkmark$ & & $\checkmark$ & \\
\hline 107 & Monomers & trans-Resveratroloside & С20H22O8 & 390.388 & 389 & $\begin{array}{c}227, \mathbf{1 8 5}, 179,269,143 \\
305,371,209\end{array}$ & 311 & MS & $\checkmark$ & $\checkmark$ & & & \\
\hline 108 & Monomers & trans-Resveratrol-2-C-glucoside & NA & NA & 389 & $269,241,299,175,163$ & 326 & MS, NMR & & $\checkmark$ & $\checkmark$ & & \\
\hline 109 & Monomers & trans-Resveratrol-10-C-glucoside & NA & NA & 435 & 389,227 & 315 & MS, NMR & & $\checkmark$ & & & \\
\hline 110 & Monomers & trans-Resveratrol-O-glucoside & $\mathrm{C} 20 \mathrm{H} 22 \mathrm{O} 8$ & 390.388 & 389 & $227,305,175,185$ & 321 & MS, NMR & & $\checkmark$ & $\checkmark$ & $\checkmark$ & \\
\hline 183 & Monomers & cis-Resveratrol-O-glucoside & $\mathrm{C} 20 \mathrm{H} 23 \mathrm{O} 8$ & 391.391 & 389 & 227 & 319,306 & MS & $\checkmark$ & & & & \\
\hline 113 & Monomers & trans-Piceid & $\mathrm{C} 20 \mathrm{H} 22 \mathrm{O} 8$ & 390.383 & 389 & $\begin{array}{c}227,185,251,269,209 \\
371,143\end{array}$ & $318,306,229$ & MS, NMR, DAD & $\checkmark$ & $\checkmark$ & $\checkmark$ & $\checkmark$ & $\checkmark$ \\
\hline 117 & Monomers & cis-Astringin & С20H22O9 & 406.383 & 405 & $\begin{array}{c}243,225,201,322,405 \\
159,228,157 \\
\end{array}$ & 324,260 & MS & $\checkmark$ & & & & \\
\hline 119 & Monomers & trans-Piceatannol & $\mathrm{C} 14 \mathrm{H} 12 \mathrm{O} 4$ & 244.246 & 243 & $\begin{array}{l}\mathbf{1 7 5 ,} 225,149,215,201 \\
159,181,132,199,143\end{array}$ & $325,290,306$ & MS, NMR & $\checkmark$ & $\checkmark$ & $\checkmark$ & $\checkmark$ & $\checkmark$ \\
\hline 120 & Monomers & cis-Resveratroloside & $\mathrm{C} 20 \mathrm{H} 22 \mathrm{O} 8$ & 390.388 & 389 & $227,371,209$ & 280 & MS & $\checkmark$ & & & & \\
\hline 121 & Monomers & cis-Piceid & $\mathrm{C} 20 \mathrm{H} 22 \mathrm{O} 8$ & 390.383 & 389 & $\begin{array}{c}227,269,241,185,209 \\
371,143\end{array}$ & 284,230 & MS, NMR & $\checkmark$ & & $\checkmark$ & & $\checkmark$ \\
\hline 122 & Monomers & trans-Isorhapontin & $\mathrm{C} 21 \mathrm{H} 24 \mathrm{O} 9$ & 420.411 & 419 & $\begin{array}{c}257,241,225,175,242 \\
201,159,281,132\end{array}$ & $326,303,290$ & MS & $\checkmark$ & & & & \\
\hline 123 & Monomers & trans-Resveratrol & $\mathrm{C} 14 \mathrm{H} 12 \mathrm{O} 3$ & 228.247 & 227 & $\begin{array}{c}185,143,183,159,157 \\
212,205\end{array}$ & $306,319,228$ & MS, NMR, DAD & $\checkmark$ & $\checkmark$ & $\checkmark$ & $\checkmark$ & $\checkmark$ \\
\hline 124 & Monomers & 2,4,6-Trihydroxyphenanthrene-2-O-glucoside & $\mathrm{C} 20 \mathrm{H} 20 \mathrm{O} 8$ & 388.372 & 389 & $\begin{array}{c}371,353,335,227,209 \\
199\end{array}$ & 261,222 & MS & $\checkmark$ & & & & \\
\hline 126 & Monomers & trans-Isorhapontigenin & C15H14O4 & 258.270 & 257 & $\begin{array}{c}242,241,224, \\
185\end{array}$ & $325,303,290$ & MS & $\checkmark$ & $\checkmark$ & $\checkmark$ & & \\
\hline 127 & Monomers & trans-Pinostilbene-4'-O-glucoside & $\mathrm{C} 21 \mathrm{H} 24 \mathrm{O} 8$ & 404.410 & 403 & $241,226,225$ & NA & MS & $\checkmark$ & & & & \\
\hline 128 & Monomers & cis-Resveratrol & $\mathrm{C} 14 \mathrm{H} 12 \mathrm{O} 3$ & 228.247 & 227 & $\begin{array}{c}\mathbf{1 8 5}, 159,143,157,212 \\
143 \\
\end{array}$ & 285,232 & MS, NMR & $\checkmark$ & & & $\checkmark$ & \\
\hline 145 & Monomers & trans-Pterostilbene & $\mathrm{C} 16 \mathrm{H} 16 \mathrm{O} 3$ & 256.296 & 255 & $239,197,209,226,165$ & $298,305,275$ & MS, NMR, DAD & $\checkmark$ & $\checkmark$ & & & \\
\hline 146 & Monomers & cis-Pterostilbene & $\mathrm{C} 16 \mathrm{H} 16 \mathrm{O} 3$ & 256.296 & 255 & $197,239,209,226,165$ & 279 & MS & $\checkmark$ & & & & \\
\hline 153 & Monomers & cis-Isorhapontigenin & C15H14O4 & 258.270 & 257 & $241,213,185,224$ & 318,220 & MS & $\checkmark$ & & & & \\
\hline 154 & Monomers & trans-Rhaponticin & $\mathrm{C} 21 \mathrm{H} 24 \mathrm{O} 9$ & 420.414 & 419 & $\begin{array}{l}257,241,281,299,323, \\
405,389,243,169,395\end{array}$ & 324,220 & MS & $\checkmark$ & & & & \\
\hline 155 & Monomers & trans-Pinostilbene & C15H14O3 & 242.270 & 241 & $181,225,197,169$ & NA & MS & $\checkmark$ & & & & \\
\hline 156 & Monomers & cis-Pinostilbene & C15H14O3 & 242.270 & 241 & $181,225,197,169$ & NA & MS & $\checkmark$ & & & & \\
\hline 111 & Dimers & Leachianol G & C28H24O7 & 472.496 & 471 & $387,377,349,255,121$ & 280,218 & MS, NMR & & $\checkmark$ & $\checkmark$ & $\checkmark$ & \\
\hline 112 & Dimers & Leachianol F & $\mathrm{C} 28 \mathrm{H} 24 \mathrm{O} 7$ & 472.496 & 471 & $\begin{array}{c}349,453,255,287,153 \\
241,121\end{array}$ & 280,218 & MS, NMR & & $\checkmark$ & $\checkmark$ & $\checkmark$ & \\
\hline 114 & Dimers & Restrytisol A & C28H24O7 & 472.486 & 471 & $377,255,349,121,471$ & 280,221 & MS & $\checkmark$ & $\checkmark$ & $\checkmark$ & & \\
\hline 115 & Dimers & Ampelopsin A & $\mathrm{C} 28 \mathrm{H} 22 \mathrm{O} 7$ & 470.479 & 469 & $\begin{array}{c}345,451,375,363,257 \\
357,423,317,241\end{array}$ & 283 & MS, NMR & & $\checkmark$ & $\checkmark$ & $\checkmark$ & $\checkmark$ \\
\hline 116 & Dimers & Pallidol & $\mathrm{C} 28 \mathrm{H} 22 \mathrm{O} 6$ & 454.478 & 453 & $\begin{array}{c}359,265,435,406,391, \\
346,273\end{array}$ & 284 & MS, NMR & $\checkmark$ & $\checkmark$ & $\checkmark$ & $\checkmark$ & $\checkmark$ \\
\hline 118 & Dimers & Caraphenol B & $\mathrm{C} 28 \mathrm{H} 22 \mathrm{O} 7$ & 470.473 & 469 & $\begin{array}{c}451,281,363,375,227 \\
423\end{array}$ & 326,291 & MS & & $\checkmark$ & $\checkmark$ & & \\
\hline
\end{tabular}


Table 2. Cont

\begin{tabular}{|c|c|c|c|c|c|c|c|c|c|c|c|c|c|}
\hline 130 & Dimers & Ampelopsin D & $\mathrm{C} 28 \mathrm{H} 22 \mathrm{O} 6$ & 454.478 & 453 & $\begin{array}{c}359,361,437,215,343 \\
199,255,289\end{array}$ & 314,280 & MS, NMR & $\checkmark$ & $\checkmark$ & $\checkmark$ & $\checkmark$ & \\
\hline 131 & Dimers & Quadrangularin A & $\mathrm{C} 28 \mathrm{H} 22 \mathrm{O} 6$ & 454.471 & 453 & $\begin{array}{l}359,289,411,435,347, \\
253\end{array}$ & 314 & MS, NMR & $\checkmark$ & $\checkmark$ & & & \\
\hline 132 & Dimers & $(+)-c i s-\varepsilon-$ Viniferin & $\mathrm{C} 28 \mathrm{H} 22 \mathrm{O} 6$ & 454.471 & 453 & $\begin{array}{c}435,347,411,333,359 \\
369,253\end{array}$ & $286,201,230$ & MS, NMR & $\checkmark$ & & & $\checkmark$ & \\
\hline 134 & Dimers & 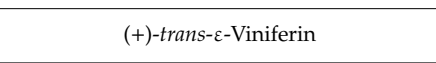 & $\mathrm{C} 28 \mathrm{H} 22 \mathrm{O} 6$ & 454.471 & 453 & $\begin{array}{c}359,435,347,369,411 \\
333,253,225\end{array}$ & $327,285,308$ & MS, NMR, DAD & $\checkmark$ & $\checkmark$ & $\checkmark$ & $\checkmark$ & $\checkmark$ \\
\hline 135 & Dimers & Viniferifuran & $\mathrm{C} 28 \mathrm{H} 20 \mathrm{O} 6$ & 452.455 & 451 & NA & $317,289,209$ & MS, NMR & & $\checkmark$ & & & \\
\hline 136 & Dimers & Diptoindonesin A & C34H32O11 & 616.610 & 615 & $453,359,411,347,585$ & 326,226 & MS, NMR & & $\checkmark$ & & $\checkmark$ & \\
\hline 141 & Dimers & trans- $\omega$-Viniferin & $\mathrm{C} 28 \mathrm{H} 22 \mathrm{O} 6$ & 454.478 & 453 & $\begin{array}{c}435,359,347,411,395 \\
333,285\end{array}$ & 324,280 & MS, NMR & $\checkmark$ & & $\checkmark$ & $\checkmark$ & $\checkmark$ \\
\hline 144 & Dimers & $c i s-\omega-$ Viniferin & $\mathrm{C} 28 \mathrm{H} 22 \mathrm{O} 6$ & 454.478 & 453 & $\begin{array}{c}435,411,395,333,285 \\
359,225\end{array}$ & 294 & MS. NMR & $\checkmark$ & & & & \\
\hline 149 & Dimers & trans- $\delta$-Viniferin & $\mathrm{C} 28 \mathrm{H} 22 \mathrm{O} 6$ & 454.478 & 453 & $\begin{array}{c}435, \mathbf{3 6 9}, \mathbf{4 1 1}, 347,333 \\
359,225,409\end{array}$ & 312,225 & MS, DAD & $\checkmark$ & $\checkmark$ & $\checkmark$ & & $\checkmark$ \\
\hline 152 & Dimers & cis- $\delta$-Viniferin & $\mathrm{C} 28 \mathrm{H} 22 \mathrm{O} 6$ & 454.478 & 453 & $\begin{array}{l}435,411,369,359,333 \\
347,317,307,251,267\end{array}$ & 285,232 & MS & $\checkmark$ & & & & \\
\hline 157 & Dimers & 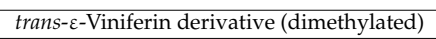 & $\mathrm{C} 30 \mathrm{H} 26 \mathrm{O} 6$ & 482.523 & 481 & $387,375,226,197,466$ & 325 & MS & $\checkmark$ & & & & \\
\hline 158 & Dimers & trans- $\delta$-Viniferin derivative (dimethylated) & $\mathrm{C} 30 \mathrm{H} 26 \mathrm{O} 6$ & 482.523 & 481 & $397,361,439,387,463$ & 313 & MS & $\checkmark$ & & & & \\
\hline 159 & Dimers & trans-Scirpusin A & $\mathrm{C} 28 \mathrm{H} 22 \mathrm{O} 7$ & 470.470 & 469 & $\begin{array}{c}375,451,385,359,241, \\
427,728,445,287,514, \\
955\end{array}$ & $320,286,204$ & MS, NMR & & $\checkmark$ & & & \\
\hline 162 & Dimers & Maackin A & $\mathrm{C} 28 \mathrm{H} 22 \mathrm{O} 8$ & 486.470 & 485 & $244,226,137$ & $327,288,204$ & MS, NMR & & $\checkmark$ & & & \\
\hline 164 & Dimers & trans- $\varepsilon$-Viniferin derivative ( $\gamma$-lactam ring) & $\mathrm{C} 32 \mathrm{H} 26 \mathrm{O} 7 \mathrm{~N}$ & 936.550 & 536 & NA & NA & MS, NMR & & & $\checkmark$ & & \\
\hline 165 & Dimers & trans-Resveratrol derivative ( $\gamma$-lactam ring) & $\mathrm{C} 18 \mathrm{H} 16 \mathrm{O} 4 \mathrm{~N}$ & 310.324 & 310 & NA & NA & MS, NMR & & & $\checkmark$ & & \\
\hline 171 & Dimers & Malibatol A & $\mathrm{C} 28 \mathrm{H} 20 \mathrm{O} 7$ & 468.454 & 467 & NA & NA & MS, NMR & & $\checkmark$ & & & \\
\hline 172 & Dimers & Ampelopsin F & $\mathrm{C} 28 \mathrm{H} 22 \mathrm{O} 6$ & 454.471 & 453 & NA & 282,220 & MS, NMR & & $\checkmark$ & & & \\
\hline 176 & Dimers & Viniferal & $\mathrm{C} 35 \mathrm{H} 26 \mathrm{O} 8$ & 574.579 & 573 & NA & NA & MS, NMR & & $\checkmark$ & & & \\
\hline 177 & Dimers & Vitisinol C & C27H24O5 & 428.482 & 427 & NA & 358,279 & MS & & & $\checkmark$ & & \\
\hline 178 & Dimers & Vitisinol E & C27H24O6 & 444.475 & 444 & NA & $281,230,204$ & MS, NMR & & $\checkmark$ & & & \\
\hline 179 & Dimers & Vitisinol B & C35H26O8 & 574.579 & 573 & NA & $282,228,204$ & MS, NMR & & & & & $\checkmark$ \\
\hline 181 & Dimers & Viniferether A & $\mathrm{C} 29 \mathrm{H} 26 \mathrm{O} 7$ & 486.509 & 485 & NA & 280,229 & MS, NMR & & & & & $\checkmark$ \\
\hline 182 & Dimers & Viniferether B & $\mathrm{C} 29 \mathrm{H} 26 \mathrm{O} 7$ & 486.513 & 485 & NA & 280,231 & MS, NMR & & 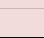 & & & $\checkmark$ \\
\hline 125 & Trimers & Ampelopsin B & $\mathrm{C} 28 \mathrm{H} 22 \mathrm{O} 6$ & 454.478 & 453 & $359,243,211,183,265$ & 281,328 & MS, NMR & $\checkmark$ & & $\checkmark$ & $\checkmark$ & \\
\hline 139 & Trimers & trans-Miyabenol C & $\mathrm{C} 42 \mathrm{H} 32 \mathrm{O} 9$ & 680.698 & 679 & $\begin{array}{c}661,573,479,451,637 \\
585,447\end{array}$ & 322,279 & MS, NMR & $\checkmark$ & $\checkmark$ & $\checkmark$ & $\checkmark$ & $\checkmark$ \\
\hline 140 & Trimers & cis-Miyabenol C & $\mathrm{C} 42 \mathrm{H} 32 \mathrm{O} 9$ & 680.699 & 679 & $\begin{array}{c}661,573,479,451,637 \\
585,447\end{array}$ & 285 & MS, NMR & $\checkmark$ & $\checkmark$ & & & \\
\hline 142 & Trimers & Davidiol A & С42H32O9 & 680.704 & 679 & $\begin{array}{c}585,447,491,385,479 \\
465,567\end{array}$ & 284,219 & MS & $\checkmark$ & $\checkmark$ & & & \\
\hline 143 & Trimers & $\alpha$-Viniferin & С42H30O9 & 678.682 & 677 & $\begin{array}{c}571,583,437,449,463, \\
501,331\end{array}$ & 284,309 & MS, NMR & $\checkmark$ & $\checkmark$ & & $\checkmark$ & \\
\hline 161 & Trimers & Ampelopsin C & $\mathrm{C} 42 \mathrm{H} 32 \mathrm{O} 9$ & 680.709 & 679 & NA & 283 & MS, NMR & & $\checkmark$ & & & $\checkmark$ \\
\hline 169 & Trimers & Viniferol D & $\mathrm{C} 42 \mathrm{H} 32 \mathrm{O} 9$ & 680.702 & 679 & NA & $\mathrm{NA}$ & MS, NMR & & $\checkmark$ & & & $\checkmark$ \\
\hline 173 & Trimers & Ampelopsin $E$ & C42H32O9 & 680.701 & 679 & NA & 325,285 & MS, NMR & & $\checkmark$ & & & $\checkmark$ \\
\hline 129 & Tetramers & Hopeaphenol & $\mathrm{C} 56 \mathrm{H} 42 \mathrm{O} 12$ & 906.925 & 905 & $\begin{array}{l}811,717,451,611,359, \\
299\end{array}$ & 283,226 & MS, NMR & & $\checkmark$ & $\checkmark$ & $\checkmark$ & $\checkmark$ \\
\hline 133 & Tetramers & Isohopeaphenol & $\mathrm{C} 56 \mathrm{H} 42 \mathrm{O} 12$ & 906.925 & 905 & $\begin{array}{c}451,675,811,717,358, \\
265\end{array}$ & 284 & MS, NMR & $\checkmark$ & $\checkmark$ & $\checkmark$ & $\checkmark$ & $\checkmark$ \\
\hline 137 & Tetramers & Ampelopsin $\mathrm{H}$ & $\mathrm{C} 56 \mathrm{H} 42 \mathrm{O} 12$ & 906.925 & 905 & $811,717,705,793$ & 281 & MS, NMR & $\checkmark$ & 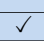 & & $\checkmark$ & \\
\hline 138 & Tetramers & Vaticanol C-like isomer & C56H42O12 & 906.929 & 905 & $811,717,793,705,611$ & 281 & MS, NMR & $\checkmark$ & & & & \\
\hline
\end{tabular}


Table 2. Cont.

\begin{tabular}{|c|c|c|c|c|c|c|c|c|c|c|c|c|}
\hline 147 & Tetramers & Vitisin A (r2-viniferin) & $\mathrm{C} 56 \mathrm{H} 42 \mathrm{O} 12$ & 906.920 & 905 & $\begin{array}{c}811,887,717,693,545, \\
451,359,265\end{array}$ & 328,285 & MS, NMR & $\checkmark$ & $\checkmark$ & $\checkmark$ & $\checkmark$ \\
\hline 148 & Tetramers & Vitisifuran A & $\mathrm{C} 56 \mathrm{H} 40 \mathrm{O} 12$ & 904.907 & 903 & NA & 322,232 & MS, NMR & $\checkmark$ & & & \\
\hline 150 & Tetramers & Vitisin B (r-viniferin) & $\mathrm{C} 56 \mathrm{H} 42 \mathrm{O} 12$ & 906.920 & 905 & $\begin{array}{c}799,887,811,717,545 \\
451,359,317\end{array}$ & 321,286 & MS, NMR & $\checkmark$ & $\checkmark$ & $\checkmark$ & $\checkmark$ \\
\hline 151 & Tetramers & Vitisifuran B & $\mathrm{C} 56 \mathrm{H} 40 \mathrm{O} 12$ & 904.907 & 903 & NA & 324,228 & MS, NMR & $\checkmark$ & & & \\
\hline 160 & Tetramers & Vitisin C & $\mathrm{C} 56 \mathrm{H} 42 \mathrm{O} 12$ & 906.926 & 905 & NA & NA & MS, NMR & $\checkmark$ & & & \\
\hline 166 & Tetramers & Viniferol A & $\mathrm{C} 56 \mathrm{H} 42 \mathrm{O} 12$ & 906.925 & 905 & $\begin{array}{c}559,813,361,453,651, \\
541,801,783\end{array}$ & 284,227 & MS, NMR & $\checkmark$ & & & \\
\hline 167 & Tetramers & Viniferol B & $\mathrm{C} 56 \mathrm{H} 42 \mathrm{O} 12$ & 906.929 & 905 & $\begin{array}{c}559,813,361,453,651 \\
541,801,783\end{array}$ & 283,225 & MS, NMR & $\checkmark$ & & & \\
\hline 168 & Tetramers & Viniferol C & $\mathrm{C} 56 \mathrm{H} 42 \mathrm{O} 12$ & 906.929 & 905 & NA & 284,228 & MS, NMR & $\checkmark$ & & & \\
\hline 170 & Tetramers & Viniferol E & $\mathrm{C} 56 \mathrm{H} 44 \mathrm{O} 13$ & 924.940 & 923 & NA & 284,231 & MS, NMR & & & & $\checkmark$ \\
\hline 174 & Tetramers & Wilsonol C & $\mathrm{C} 56 \mathrm{H} 42 \mathrm{O} 12$ & 906.929 & 905 & NA & 231 & NMR & & & & $\checkmark$ \\
\hline 175 & Tetramers & Heyneanol A & $\mathrm{C} 56 \mathrm{H} 42 \mathrm{O} 12$ & 906.929 & 905 & 320,284 & 322,237 & NMR & & & & $\checkmark$ \\
\hline 180 & Tetramers & Stenophyllol C & C56H42O12 & 906.923 & 905 & NA & $285,330,223$ & MS, NMR & & & & $\checkmark$ \\
\hline 163 & Hexamers & Viniphenol A & $\mathrm{C} 84 \mathrm{H} 64 \mathrm{O} 18$ & 1361.391 & 1360 & NA & NA & MS, NMR & $\checkmark$ & & & \\
\hline
\end{tabular}

${ }^{1}$ Other reported names are found in Table S2, where compounds are numbered (ID) according to their elution patterns. ${ }^{2}$ Another stilbene is reported in the literature as vitisinol $\mathrm{E}$ (compound 178), but with the formula $\mathrm{C}_{29} \mathrm{H}_{26} \mathrm{O}_{7}, \mathrm{MW}$ of 486,51, [M- H] - (m/z) of 485, $\lambda$ max $\mathrm{CH}_{3} \mathrm{OH}$ of 358, 279, 253. ${ }^{3} \mathrm{NA}=$ not available or not applicable, MW = Molecular Weight. ${ }^{4}$ The most abundant fragments are highlighted in bold. ${ }^{5} \mathrm{MS}=$ mass spectrometry detection, NMR = nuclear magnetic resonance detection, $\mathrm{DAD}=$ diode array or ultraviolet detection.

${ }^{6}$ In blue with $\sqrt{ }$ are detected compounds; in light red are undetected compounds or unavailable information. 
The basic simple structure of stilbenes gives rise to a wide array of compounds that primarily vary in the number and position of hydroxyl groups and various substitutions with sugars, methyl, and methoxy groups, in addition to the structural conformations of the molecules and oligomerization patterns $[8,31,39,68]$.

\subsection{Monomeric Stilbenes}

Of the total known $V$. vinifera stilbenes, 23 are monomers: trans-astringin, cis-astringin, trans -resveratroloside, cis-resveratroloside, trans-resveratrol-2-C-glucoside, trans-resveratrol-10-C-glucoside, trans-resveratrol-O-glucoside, cis-resveratrol-O-glucoside, trans-piceid, cis-piceid, trans-piceatannol, trans-isorhapontin, trans-resveratrol, cis-resveratrol, 2,4,6-trihydroxyphenanthrene-2-O-glucoside, trans-isorhapontigenin, cis-isorhapontigenin, trans-pinostilbene, cis-pinostilbene, trans-pinostilbene4'-O-glucoside (or trans-pinostilbene-3-O-glucoside by some authors), trans-pterostilbene, cis-pterostilbene, and trans-rhaponticin (or trans-rhapontin by some authors) (Table 2) [7,31,40,50,53].

\subsection{Dimeric Stilbenes}

The majority of the stilbenoids in grapevine vegetative organs are dimers (30 in total): leachianol G, leachianol F, restrytisol A, ampelopsin A, ampelopsin D, ampelopsin F, pallidol, caraphenol $\mathrm{B}$, quadrangularin, (+)-trans- $\varepsilon$-viniferin (and occasionally (-)-trans- $\varepsilon$-viniferin), (+)-cis- $\varepsilon$-viniferin (and occasionally (-)-cis- $\varepsilon$-viniferin), viniferifuran (reported as amurensin $\mathrm{H}$ by some authors), diptoindonesin A (reported as $\varepsilon$-viniferin-C-glucoside by some authors), trans- $\omega$-viniferin, cis- $\omega$-viniferin, trans- $\delta$-viniferin, cis- $\delta$-viniferin, a dimethylated derivative of trans- $\varepsilon$-viniferin, a dimethylated derivative of trans- $\delta$-viniferin, trans-scirpusin $\mathrm{A}$, maackin $\mathrm{A}$, a derivative of trans- $\varepsilon$-viniferin with $\gamma$-lactam ring, a derivative of trans-resveratrol with $\gamma$-lactam ring, malibatol A, viniferal, vitisinol $C$, vitisinol $E$, vitisinol $B$, viniferether $A$, and viniferether $B$ (Table 2). It is important to note that there are a number of instances where common names given to particular stilbenoids can lead to confusion. For instance, the name vitisinol $\mathrm{E}$ has been given to two different stilbenoid dimers by different authors $[8,25-28,62]$.

\subsection{Trimeric Stilbenes}

There are eight trimers in $V$. vinifera vegetative organs: ampelopsin $\mathrm{B}$, ampelopsin $\mathrm{C}$, ampelopsin E, trans-miyabenol C, cis-miyabenol C, davidiol A, $\alpha$-viniferin, and viniferol D (Table 2) $[9,31,56,57,67]$.

\subsection{Tetrameric Stilbenes}

Among stilbene tetramers, the following 16 compounds are reported in the vegetative organs of grapevine: hopeaphenol, isohopeaphenol, ampelopsin $\mathrm{H}$, vaticanol C-like isomer (or vaticanol $\mathrm{C}$ by some authors), vitisin A (r2-viniferin), vitisin B (r-viniferin), vitisifuran A, vitisifuran B, vitisin $C$, viniferol A, viniferol B, viniferol C, viniferol E, wilsonol C, heyneanol A, and stenophyllol C (reported as napalensinol B by some authors) (Table 2) $[7,25,28,29,31,41,67]$.

\subsection{Pentameric Stilbenes}

Two stilbenes pentamers have been reported in the Vitis genus [39]. However, none have been detected in the vegetative organs.

\subsection{Hexameric Stilbenes}

Viniphenol A, a new resveratrol hexamer, is the only hexameric stilbene isolated from $V$. vinifera leaves (Table 2) [26]. 


\section{Levels of Phenolic Compounds in the Leaves, Stems, Canes, Woods, and Roots of the Vine Plant}

Several phenolic compounds have been quantified in grapevine, although absolute quantification is currently not available for many of them $[9,55,59]$. Most authors have reported their data on either a fresh or dry weigh basis (Tables S1 and S2). In analyzing the data for this review, mean values were first calculated using fresh and dry weight values separately, and then together. Although the separate analysis proved challenging because of few data points available for many of the compounds, the final ranking of phenolics was not affected by the method of calculation.

On another note, many of the compounds are quantified as equivalents of the most similar chemicals $[12,13,51]$. Comparison of the calibration curves showed that assays of content determination in vine of stilbenes in which equivalent chemicals are used as standards lead to a severe underestimation of the oligomer concentration. For example, the quantification of $\varepsilon$-viniferin using trans-resveratrol as standard underestimated its concentration by a factor $>2$ in the study by [24]. Therefore, caution is required when interpreting the data presented in Tables 3-10, taking into consideration the water status of the samples analyzed as reported by the different authors, and the number of studies and data points used in the calculation of mean values (Tables S1 and S2).

Table 3. Levels (mg/kg) of 92 polyphenols (excluding stilbenes) identified in grapevine leaves.

\begin{tabular}{|c|c|c|c|c|c|c|c|}
\hline Id & Compound Name ${ }^{1}$ & $\begin{array}{l}\text { Minimum } \\
\text { Value }^{2,3}\end{array}$ & $\begin{array}{l}\text { Maximum } \\
\text { Value }\end{array}$ & $\begin{array}{l}\text { Mean } \\
\text { Value }^{4}\end{array}$ & $\begin{array}{l}\text { Standard } \\
\text { Deviation }\end{array}$ & $N^{5}$ & References \\
\hline 63 & Quercetin-3-O-glucuronide & 868.63 & $46,528.55$ & $10,305.10$ & $13,363.51$ & 10 & $\begin{array}{c}1,2,4,5,19,59,60,66 \\
75,79,81,82,84-86]\end{array}$ \\
\hline 58 & Quercetin-3-O-galactoside & 21.72 & $28,831.11$ & 7436.94 & 9880.90 & 14 & $\begin{array}{c}{[2,3,5,20,22,73,75,79} \\
81,85]\end{array}$ \\
\hline 60 & Quercetin-3-O-glucoside & 27.65 & $22,610.13$ & 7256.42 & 7628.71 & 24 & $\begin{array}{c}{[1-3,5,19,20,22,59} \\
60,66,73,75,79-82 \\
84-86]\end{array}$ \\
\hline 24 & Caftaric acid & 12.46 & $14,052.62$ & 4151.97 & 3984.79 & 18 & $\begin{array}{c}{[3-5,19,20,22,59,60} \\
66,73,75,79,81,82 \\
84-86]\end{array}$ \\
\hline 69 & Quercetin-3-O-rhamnoside & 1210.53 & 4206.67 & 2708.60 & 1498.07 & 2 & $\begin{array}{c}{[1,2]} \\
{[2,3,19,20,22,59,60}\end{array}$ \\
\hline 79 & Kaempferol-3-O-glucoside & 2.56 & 6203.85 & 1730.09 & 1812.15 & 20 & $\begin{array}{c}\text { 66,73,75,79-81,84- } \\
86]\end{array}$ \\
\hline 73 & Kaempferol-3-O-glucuronide & 47.92 & 1698.41 & 662.34 & 736.83 & 3 & $\begin{array}{c}{[2,19,66,79,81,82,85} \\
86]\end{array}$ \\
\hline 27 & Coutaric acid & 4.54 & 1491.02 & 635.81 & 432.70 & 10 & $\begin{array}{c}{[3,19,20,22,73,75,79} \\
81,82,85]\end{array}$ \\
\hline 53 & Myricetin-3-O-glucoside & ND & 850.12 & 291.23 & 254.65 & 8 & {$[2,3,20,22,73,85]$} \\
\hline 54 & Quercetin-3-O-rutinoside & 1.30 & 1650.01 & 257.51 & 473.26 & 12 & $\begin{array}{c}{[2,4,5,32,73,75,79,81,} \\
82,85,87]\end{array}$ \\
\hline 71 & Kaempferol-3-O-rutinoside & 0.12 & 730.01 & 200.34 & 307.13 & 4 & {$[2,19,75,79,81,85,86]$} \\
\hline 32 & Fertaric acid & 85.48 & 85.48 & 85.48 & 0.00 & 1 & {$[81,82]$} \\
\hline 7 & $p$-Hydroxybenzoic acid & 15.80 & 151.00 & 83.40 & 67.60 & 2 & {$[19,32]$} \\
\hline 42 & Gallocatechin gallate & 20.10 & 78.70 & 49.40 & 29.30 & 2 & [32] \\
\hline 68 & Myricetin & 1.00 & 193.28 & 44.75 & 74.37 & 5 & {$[1,3,22,81,88]$} \\
\hline 3 & Gallocatechin & 4.84 & 102.00 & 40.20 & 43.85 & 3 & {$[32,81,82]$} \\
\hline 5 & Aesculin & 1.60 & 50.70 & 25.63 & 20.06 & 3 & {$[32,81]$} \\
\hline 15 & Epigallocatechin & 1.67 & 66.30 & 23.77 & 30.08 & 3 & {$[32,81,82]$} \\
\hline 37 & Epigallocatechin gallate & 0.04 & 43.81 & 10.69 & 16.71 & 6 & {$[32,73,81,82]$} \\
\hline 23 & Catechin & 0.02 & 76.58 & 10.62 & 21.44 & 18 & $\begin{array}{l}{[19,32,59,60,73,75,} \\
79,81,82,84,87,88]\end{array}$ \\
\hline 46 & Ferulic acid & 0.008 & 89.80 & 9.07 & 25.61 & 11 & $\begin{array}{c}{[32,59,60,73,79,81} \\
84]\end{array}$ \\
\hline 82 & Quercetin & 0.13 & 52.17 & 8.84 & 16.55 & 16 & $\begin{array}{c}{[1,4,19,32,59,60,73} \\
84,87,88]\end{array}$ \\
\hline 6 & Procyanidin B1 & 0.39 & 25.56 & 6.80 & 10.83 & 4 & {$[73,75,79,81,82]$} \\
\hline 4 & Protocatechuic acid & 1.25 & 10.50 & 5.88 & 4.63 & 2 & [32] \\
\hline 8 & Gentisic acid & 0.59 & 8.85 & 4.72 & 4.13 & 2 & {$[32]$} \\
\hline 11 & Phlorizin & 2.95 & 2.95 & 2.95 & 0.00 & 1 & {$[81,82]$} \\
\hline 2 & Gallic acid & 0.01 & 7.80 & 2.77 & 2.95 & 9 & {$[32,79,81,82,87,88]$} \\
\hline 78 & Quercetin-3-(3-O-rhamnosyl)glucoside-7-O-rhamnoside & 1.32 & 4.21 & 2.77 & 1.44 & 2 & [1] \\
\hline 40 & Epicatechin & 0.01 & 15.02 & 2.46 & 4.69 & 18 & $\begin{array}{c}{[32,59,60,73,75,79} \\
81,82,84,87,88]\end{array}$ \\
\hline 94 & Quercetin-3-(6-O-rhamnosyl)galactoside & 0.02 & 4.02 & 2.02 & 2.00 & 2 & [1] \\
\hline
\end{tabular}


Table 3. Cont.

\begin{tabular}{|c|c|c|c|c|c|c|c|}
\hline Id & Compound Name ${ }^{1}$ & $\begin{array}{l}\text { Minimum } \\
\text { Value }{ }^{2,3}\end{array}$ & $\begin{array}{l}\text { Maximum } \\
\text { Value }\end{array}$ & $\begin{array}{c}\text { Mean } \\
\text { Value }^{4}\end{array}$ & $\begin{array}{l}\text { Standard } \\
\text { Deviation }\end{array}$ & $N^{5}$ & References \\
\hline 29 & Procyanidin B2 & 0.35 & 5.69 & 1.91 & 2.21 & 4 & {$[75,79,81,82]$} \\
\hline 47 & Epicatechin gallate & 0.01 & 8.45 & 1.74 & 2.57 & 9 & {$[59,60,81,82,84,88]$} \\
\hline 28 & Chlorogenic acid & 0.01 & 11.50 & 1.74 & 3.70 & 8 & {$[32,73,79,88]$} \\
\hline 35 & Caffeic acid & 0.003 & 19.60 & 1.68 & 4.84 & 15 & $\begin{array}{c}{[1,32,59,73,79,81,82} \\
84,87,88]\end{array}$ \\
\hline 25 & Procyanidin B3 & 0.74 & 2.41 & 1.57 & 0.84 & 2 & {$[75,81,82]$} \\
\hline 26 & Procyanidin B4 & 0.61 & 2.38 & 1.49 & 0.89 & 2 & {$[75,81,86]$} \\
\hline 93 & Isorhamnetin-3-O-glucoside & 1.48 & 1.48 & 1.48 & 0.00 & 1 & {$[2,80,81,85]$} \\
\hline 84 & Kaempferol & 0.01 & 6.77 & 1.28 & 2.19 & 8 & {$[1,32,59,60,84,86,88]$} \\
\hline 34 & Cyanidin-3-O-glucoside & 0.01 & 6.40 & 1.17 & 2.04 & 8 & $\begin{array}{c}{[4,5,59,60,77-79,84} \\
88]\end{array}$ \\
\hline 98 & Isorhamnetin-3-O-rutinoside & 1.12 & 1.12 & 1.12 & 0.00 & 1 & {$[2,81]$} \\
\hline 43 & $p$-Coumaric acid & 0.01 & 8.17 & 0.92 & 2.42 & 10 & {$[32,59,60,79,84,88]$} \\
\hline 64 & Apigenin-7-O-glucoside & 0.09 & 1.60 & 0.85 & 0.75 & 2 & [1] \\
\hline 10 & Procyanidin A1 & 0.72 & 0.72 & 0.72 & 0.00 & 1 & {$[75]$} \\
\hline 66 & Luteolin-7-O-glucoside & 0.02 & 1.91 & 0.60 & 0.69 & 5 & {$[1,4,73,81,82]$} \\
\hline 48 & Sinapic acid & 0.55 & 0.55 & 0.55 & 0.00 & 1 & [81] \\
\hline 50 & Ellagic acid & 0.06 & 0.77 & 0.41 & 0.36 & 2 & [32] \\
\hline 41 & Taxifolin & 0.37 & 0.37 & 0.37 & 0.00 & 1 & [81] \\
\hline 83 & Cinnamic acid & 0.17 & 0.51 & 0.34 & 0.17 & 2 & [79] \\
\hline 75 & Quercetin-3-(3-O-arabinosyl)glucoside & 0.31 & 0.31 & 0.31 & 0.00 & 1 & {$[2,81]$} \\
\hline 89 & Kaempferol-3-O-xyloside & 0.23 & 0.23 & 0.23 & 0.00 & 1 & {$[2,75]$} \\
\hline 45 & Peonidin-3-O-glucoside & 0.01 & 0.60 & 0.20 & 0.24 & 4 & {$[5,77-79,88]$} \\
\hline 30 & Vanillic acid & 0.01 & 0.54 & 0.19 & 0.19 & 5 & {$[77-79,81,88]$} \\
\hline 14 & 1-O-Sinapoyl- $\beta$-D-glucose & 0.15 & 0.15 & 0.15 & 0.00 & 1 & [75] \\
\hline 70 & Kaempferol-3-O-galactoside & 0.06 & 0.06 & 0.06 & 0.00 & 1 & {$[2,75,85,86]$} \\
\hline 36 & Syringic acid & 0.01 & 0.07 & 0.04 & 0.03 & 2 & [88] \\
\hline 52 & Malvidin-3-O-glucoside & 0.01 & 0.06 & 0.04 & 0.03 & 2 & $\begin{array}{c}{[1-5,19,32,59,66,75,} \\
77-82,84-86,88]\end{array}$ \\
\hline 16 & 1-O-(4-Coumaroyl)-glucose & 0.03 & 0.03 & 0.03 & 0.00 & 1 & [75] \\
\hline 1 & Quinic acid & NQ & NQ & NQ & NQ & 0 & {$[4,19]$} \\
\hline 9 & $\gamma$-Resorcylic acid & NQ & NQ & NQ & NQ & 0 & [82] \\
\hline 12 & Fraxin & NQ & NQ & NQ & $\mathrm{NQ}$ & 0 & [82] \\
\hline 13 & Aesculetin & NQ & NQ & NQ & NQ & 0 & [19] \\
\hline 17 & Umbelliferone & NQ & NQ & NQ & NQ & 0 & [19] \\
\hline 20 & 1-Caffeoyl- $\beta$-D-glucose & NQ & NQ & NQ & NQ & 0 & [81] \\
\hline 21 & Ferulic acid pentose & NQ & NQ & NQ & NQ & 0 & [19] \\
\hline 22 & Caftaric acid isomer & NQ & NQ & NQ & NQ & 0 & [85] \\
\hline 33 & Delphinidin-3-O-glucoside & NQ & NQ & NQ & NQ & 0 & {$[77-79]$} \\
\hline 44 & Petunidin-3-O-glucoside & NQ & NQ & NQ & NQ & 0 & {$[77-79]$} \\
\hline 49 & Myricetin-3-O-galactoside & NQ & NQ & NQ & NQ & 0 & {$[2,79,85]$} \\
\hline 51 & Myricetin-3-O-glucuronide & NQ & NQ & NQ & NQ & 0 & {$[2,79]$} \\
\hline 59 & Petunidin-3-(6-O-acetyl)glucoside & NQ & NQ & NQ & NQ & 0 & [77] \\
\hline 61 & Catechin gallate & NQ & NQ & NQ & NQ & 0 & [86] \\
\hline 62 & Peonidin-3-(6-O-acetyl)glucoside & NQ & NQ & NQ & NQ & 0 & [79] \\
\hline 65 & Myricetin-3-O-rhamnoside & NQ & NQ & NQ & NQ & 0 & [2] \\
\hline 67 & Malvidin-3-(6-O-acetyl)glucoside & NQ & NQ & NQ & NQ & 0 & {$[77,79]$} \\
\hline 72 & Cyanidin-3-(6-O-coumaroyl)glucoside & NQ & NQ & NQ & NQ & 0 & [77] \\
\hline 74 & Quercetin-3-(6-O-acetyl)glucoside & NQ & NQ & NQ & NQ & 0 & [19] \\
\hline 76 & Quercetin-3-(7-O-glucosyl)glucuronide & NQ & NQ & NQ & NQ & 0 & [80] \\
\hline 80 & Petunidin-3-(6-O-coumaroyl)glucoside & NQ & NQ & NQ & NQ & 0 & [77] \\
\hline 81 & Peonidin-3-(6-O-coumaroyl)glucoside & NQ & NQ & NQ & NQ & 0 & {$[2,77,79]$} \\
\hline 85 & Malvidin-3-(6-O-coumaroyl)glucoside & NQ & NQ & NQ & NQ & 0 & {$[77,79]$} \\
\hline 88 & Hesperetin & NQ & NQ & NQ & NQ & 0 & [4] \\
\hline 90 & Kaempferol-3-O-rhamnoside & NQ & NQ & NQ & NQ & 0 & [2] \\
\hline 92 & Isorhamnetin-3-O-galactoside & NQ & NQ & NQ & NQ & 0 & {$[2,85]$} \\
\hline 95 & Eriodictyol-7-O-glucoside & NQ & NQ & NQ & NQ & 0 & [19] \\
\hline 96 & Isorhamnetin-3-O-arabinose & NQ & NQ & NQ & NQ & 0 & [2] \\
\hline 97 & Isorhamnetin-3-O-glucuronide & NQ & NQ & NQ & NQ & 0 & [2] \\
\hline 100 & Isorhamnetin-3(4-O-rhamnosyl)rutinoside & NQ & NQ & NQ & NQ & 0 & {$[2,80,85]$} \\
\hline 101 & Kaempferol-3-(6-O-coumaroyl)glucoside & NQ & NQ & NQ & NQ & 0 & [4] \\
\hline 102 & Kaempferol-3 (7-O-glucosyl)galactoside & NQ & NQ & NQ & NQ & 0 & {$[80]$} \\
\hline 103 & Naringenin & NQ & NQ & NQ & NQ & 0 & [82] \\
\hline 104 & Naringenin-7-O-glucoside & NQ & NQ & NQ & NQ & 0 & [82] \\
\hline 105 & Diquercetin-3-(3-O-glucosyl)glucuronide & NQ & NQ & NQ & NQ & 0 & [66] \\
\hline
\end{tabular}

${ }^{1}$ Compounds 33, 43, 52, 59, 62, 67, 72, 76, 80, 83, 85, and 102 are detected using only UV. ${ }^{2} \mathrm{ND}=$ not detected. ${ }^{3} \mathrm{NQ}=$ not quantified by the authors. ${ }^{4}$ Fresh and dry weight data were combined for the calculations, without any conversion. ${ }^{5} \mathrm{~N}=$ number of data points used in the calculation of the mean value, and made of minimum, maximum, and average values extracted from each reference. 
Table 4. Levels $(\mathrm{mg} / \mathrm{kg}$ ) of 40 stilbenic compounds identified in grapevine leaves.

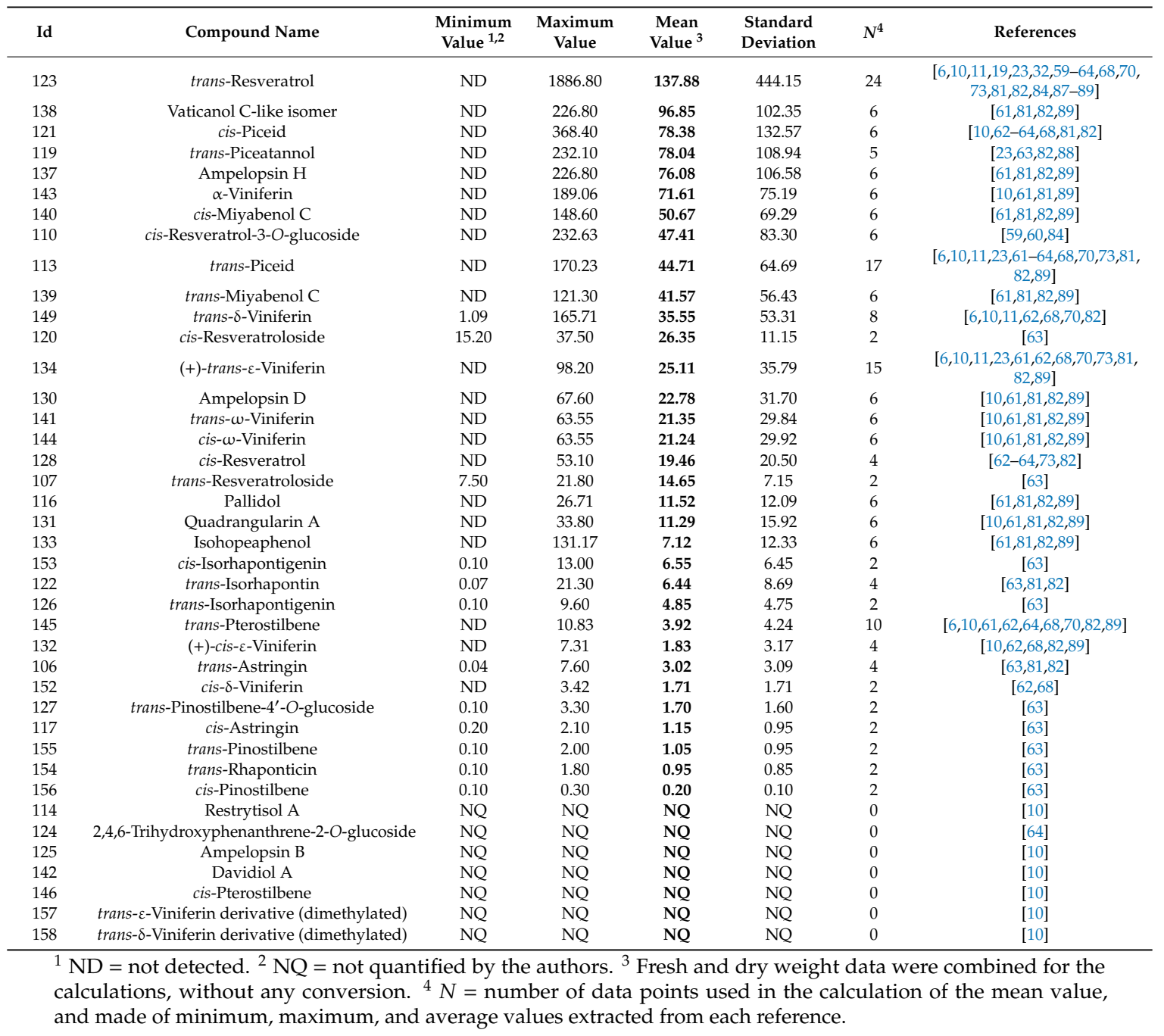

\subsection{Phenolic Compounds in Grapevine Leaves}

A total of 132 phenolic compounds have been reported in grapevine leaves (Tables 3 and 4).

Eighty-seven phenolic acids and flavonoids, and five coumarins have been identified in the leaves of grapevine, with the highest level recorded for quercetin-3-O-glucuronide $(10,305.10 \mathrm{mg} / \mathrm{kg}$ on average), followed by quercetin-3-O-galactoside $(7436.94 \mathrm{mg} / \mathrm{kg})$, quercetin-3-O-glucoside $(7256.42 \mathrm{mg} / \mathrm{kg})$, caftaric acid $(4151.97 \mathrm{mg} / \mathrm{kg})$, quercetin-3-O-rhamnoside $(2708.60 \mathrm{mg} / \mathrm{kg})$, kaempferol-3-O-glucoside (1730.09 mg/kg), kaempferol-3-O-glucuronide $(662.34 \mathrm{mg} / \mathrm{kg})$, coutaric acid $(635.81 \mathrm{mg} / \mathrm{kg})$, myricetin-3-O-glucoside $(291.23 \mathrm{mg} / \mathrm{kg})$, quercetin-3-O-rutinoside $(257.51 \mathrm{mg} / \mathrm{kg})$, and kaempferol-3-O-rutinoside $(200.34 \mathrm{mg} / \mathrm{kg}$ ) (Table 3). Among compounds with levels between 10 and $100 \mathrm{mg} / \mathrm{kg}$ are five favan-3-ols (gallocatechin gallate, $49.40 \mathrm{mg} / \mathrm{kg}$; gallocatechin, $40.20 \mathrm{mg} / \mathrm{kg}$; epigallocatechin, $23.77 \mathrm{mg} / \mathrm{kg}$; epigallocatechin gallate, $10.69 \mathrm{mg} / \mathrm{kg}$; and catechin; $10.62 \mathrm{mg} / \mathrm{kg}$ ), and two phenolic acids (fertaric acid, $85.48 \mathrm{mg} / \mathrm{kg}$; and p-hydroxybenzoic acid, $83.40 \mathrm{mg} / \mathrm{kg}$ ) (Table 3). These levels in general agree with reports that grapevine leaves are rich sources of flavonols. In their studies, $[2,20,22,79,84,85]$ found that the predominant phenolics in the leaves are quercetin-3-O-glucuronide, quercetin-3-O-glucoside, caftaric acid, and kaempferol-3-O-glucoside; total amounts of quercetin derivatives were significantly higher than total amounts of kaempferol derivatives in the studies $[2,79,85]$. 
Table 5. Levels (mg/kg) of 41 polyphenols (excluding stilbenes) identified in grapevine stems.

\begin{tabular}{|c|c|c|c|c|c|c|c|}
\hline Id & Compound Name ${ }^{1}$ & $\begin{array}{c}\text { Minimum } \\
\text { Value }^{2}\end{array}$ & $\begin{array}{l}\text { Maximum } \\
\text { Value }\end{array}$ & $\begin{array}{l}\text { Mean } \\
\text { Value }^{3}\end{array}$ & $\begin{array}{c}\text { Standard } \\
\text { Deviation }\end{array}$ & $N^{4}$ & References \\
\hline 58 & Quercetin-3-O-galactoside & 1920.34 & $41,831.70$ & $17,403.61$ & $15,457.56$ & 4 & {$[21,50]$} \\
\hline 23 & Catechin & 283.72 & $98,290.95$ & $14,900.45$ & $27,191.10$ & 12 & {$[9,21,37,50,53,55,69,74,90]$} \\
\hline 40 & Epicatechin & 193.61 & $33,154.03$ & 9251.64 & $12,435.12$ & 14 & {$[9,21,33,50,53-55,69,90]$} \\
\hline 6 & Procyanidin B1 & 215.36 & $50,709.00$ & 9216.18 & $14,385.61$ & 10 & {$[9,33,37,50,53-55,69]$} \\
\hline 19 & Procyanidin T2 & 1388.90 & $35,015.04$ & 9100.99 & 8406.54 & 2 & {$[9,34,50,55,69]$} \\
\hline 25 & Procyanidin B3 & 186.04 & $23,108.65$ & 8724.23 & 5791.29 & 4 & {$[9,21,55,69]$} \\
\hline 82 & Quercetin & 321.88 & 8210.20 & 4266.04 & 3944.16 & 2 & [21] \\
\hline 24 & Caftaric acid & 110.35 & $16,110.62$ & 3373.18 & 5723.49 & 6 & {$[33,54,74,87]$} \\
\hline 26 & Procyanidin B4 & 131.00 & 4355.20 & 2243.10 & 2112.10 & 2 & [69] \\
\hline 39 & Procyanidin dimer gallate & 110.04 & 4358.12 & 2234.08 & 2124.04 & 2 & {$[9,33,34,50,54,69]$} \\
\hline 29 & Procyanidin B2 & 10.49 & 6670.76 & 2056.93 & 2735.52 & 4 & {$[9,21,50,53,55,69,74]$} \\
\hline 60 & Quercetin-3-O-glucoside & 29.88 & 7270.12 & 1785.38 & 2544.06 & 6 & {$[9,21,37,53,55,90]$} \\
\hline 69 & Quercetin-3-O-rhamnoside & 320.20 & 2820.00 & 1570.10 & 1249.90 & 2 & [21] \\
\hline 52 & Malvidin-3-O-glucoside & 224.88 & 801.37 & 513.13 & 288.25 & 4 & {$[33,54]$} \\
\hline 43 & $p$-Coumaric acid & 12.00 & 934.08 & 473.04 & 461.04 & 2 & {$[9,21,55]$} \\
\hline 35 & Caffeic acid & 10.18 & 647.32 & 328.75 & 318.57 & 2 & {$[9,21,55]$} \\
\hline 38 & Prodelphinidin A-type & 27.46 & 292.88 & 160.17 & 132.71 & 2 & {$[33,50,54]$} \\
\hline 99 & Isorhamnetin-3-(6-O-feruloyl)glucoside & 81.10 & 115.07 & 98.09 & 16.99 & 4 & {$[33,54]$} \\
\hline 86 & Malvidin-3-(6-O-caffeoyl)glucoside & 47.33 & 119.20 & 83.27 & 35.94 & 4 & {$[33,54]$} \\
\hline 71 & Kaempferol-3-O-rutinoside & 21.99 & 127.39 & 74.69 & 52.70 & 4 & {$[33,54]$} \\
\hline 54 & Quercetin-3-O-rutinoside & 10.55 & 126.73 & 65.84 & 46.33 & 6 & {$[21,33,34,54,74,90]$} \\
\hline 79 & Kaempferol-3-O-glucoside & 20.14 & 79.08 & 49.61 & 29.47 & 4 & {$[33,54]$} \\
\hline 36 & Syringic acid & 6.48 & 32.23 & 19.36 & 12.88 & 2 & [21] \\
\hline 46 & Ferulic acid & 8.01 & 25.55 & 16.78 & 8.77 & 2 & {$[9,21,55]$} \\
\hline 16 & 1-O-(4-Coumaroyl)-glucose & NQ & NQ & NQ & NQ & 0 & [53] \\
\hline 20 & 1-Caffeoyl- $\beta$-D-glucose & NQ & NQ & NQ & NQ & 0 & [53] \\
\hline 21 & Ferulic acid pentose & NQ & NQ & NQ & NQ & 0 & {$[9,55]$} \\
\hline
\end{tabular}

The 40 stilbenes reported in the leaves of $V$. vinifera are eminently less abundant than the phenolic acids and flavonoids. The most predominant stilbenes in the leaves with levels superior to $50 \mathrm{mg} / \mathrm{kg}$ are trans-resveratrol $(137.88 \mathrm{mg} / \mathrm{kg})$, vaticanol C-like isomer $(96.85 \mathrm{mg} / \mathrm{kg})$, cis-piceid (78.38 mg/kg), trans-piceatannol (78.04 mg/kg), ampelopsin H (76.08 mg/kg), $\alpha$-viniferin $(71.61 \mathrm{mg} / \mathrm{kg})$, and cis-miyabenol C (50.37 mg/kg) (Table 4). All these compounds are often undetected in healthy leaves. For example, in two grapevine varieties grown in Serbia, the total stilbene content was $45 \%$ higher in infected than in healthy leaf extracts [73]. Interestingly, some leaf samples have been found to contain cis-resveratrol-3-O-glucoside instead of the expected trans-resveratrol as their predominant stilbene $[59,60,84]$.

\subsection{Phenolic Compounds in Grapevine Stems}

Literature data have revealed the presence of 88 phenolic compounds (of which 47 were stilbenes) in the stems of grapevine. Although the most abundant compound is the flavonol quercetin-3-O-galactoside $(17,403.61 \mathrm{mg} / \mathrm{kg})$, flavan-3-ols constitute the majority of compounds in the stems and in the order catechin $(14,900.45 \mathrm{mg} / \mathrm{kg})>$ gallic acid $(10,307.36 \mathrm{mg} / \mathrm{kg})>$ epicatechin $(9251.64 \mathrm{mg} / \mathrm{kg})>$ procyanidin B1 $(9216.18 \mathrm{mg} / \mathrm{kg})>$ procyanidin T2 $(9100.99 \mathrm{mg} / \mathrm{kg})>$ procyanidin B3 $(8724.23 \mathrm{mg} / \mathrm{kg})>$ epicatechin gallate $(6362.96 \mathrm{mg} / \mathrm{kg})>$ procyanidin $\mathrm{C} 1(5007.76 \mathrm{mg} / \mathrm{kg})>$ procyanidin B4 $(2243.10 \mathrm{mg} / \mathrm{kg})>$ procyanidin dimer gallate $(2234.08 \mathrm{mg} / \mathrm{kg})>$ procyanidin B2 $(2056.93 \mathrm{mg} / \mathrm{kg})$ $>$ procyanidin A1 $(1254.38 \mathrm{mg} / \mathrm{kg}$ ) (Table 5). The high level of flavan-3-ols in the stems agrees with several reports $[33,34,37,54,69]$. Among other compounds with average values superior to $900 \mathrm{mg} / \mathrm{kg}$ 
are the phenolic acid caftaric acid $(3373.18 \mathrm{mg} / \mathrm{kg})$ and the flavonols quercetin $(4266.04 \mathrm{mg} / \mathrm{kg})$, quercetin-3-O-glucoside (1785.38 mg/kg), quercetin-3-O-rhamnoside (1570.10 mg/kg), kaempferol $(950.35 \mathrm{mg} / \mathrm{kg})$, and quercetin-3-O-glucuronide $(908.82 \mathrm{mg} / \mathrm{kg})$, which are also abundant compounds in the leaves. In the stems, two anthocyanins are reported with average values superior to $500 \mathrm{mg} / \mathrm{kg}$, namely, malvidin-3-O-rutinoside $(539.89 \mathrm{mg} / \mathrm{kg}$ ) and malvidin-3-O-glucoside $(513.13 \mathrm{mg} / \mathrm{kg}$ ) (Table 5). In the stems from seven cultivars grown in northern Portugal, caftaric acid, quercetin-3-O-glucuronide, malvidin derivatives, and epicatechin were the main metabolites, representing from $54 \%$ to $75 \%$ of the total phenolic content [33].

Only a few of the 47 stilbenic compounds identified in the stems of grapevine have been quantified [58]: trans-resveratrol (506.41 mg/kg), (+)-trans- $\varepsilon$-viniferin $(433.49 \mathrm{mg} / \mathrm{kg})$, ampelopsin D $(65.00 \mathrm{mg} / \mathrm{kg})$, vitisin B $(33.95 \mathrm{mg} / \mathrm{kg})$, trans-piceid $(14.52 \mathrm{mg} / \mathrm{kg})$, trans-isorhapontigenin $(9.90 \mathrm{mg} / \mathrm{kg})$, trans-piceatannol $(7.42 \mathrm{mg} / \mathrm{kg})$, and trans- $\delta$-viniferin $(4.86 \mathrm{mg} / \mathrm{kg})($ Table 6$)$.

Table 6. Levels (mg/kg) of 47 stilbenic compounds identified in grapevine stems.

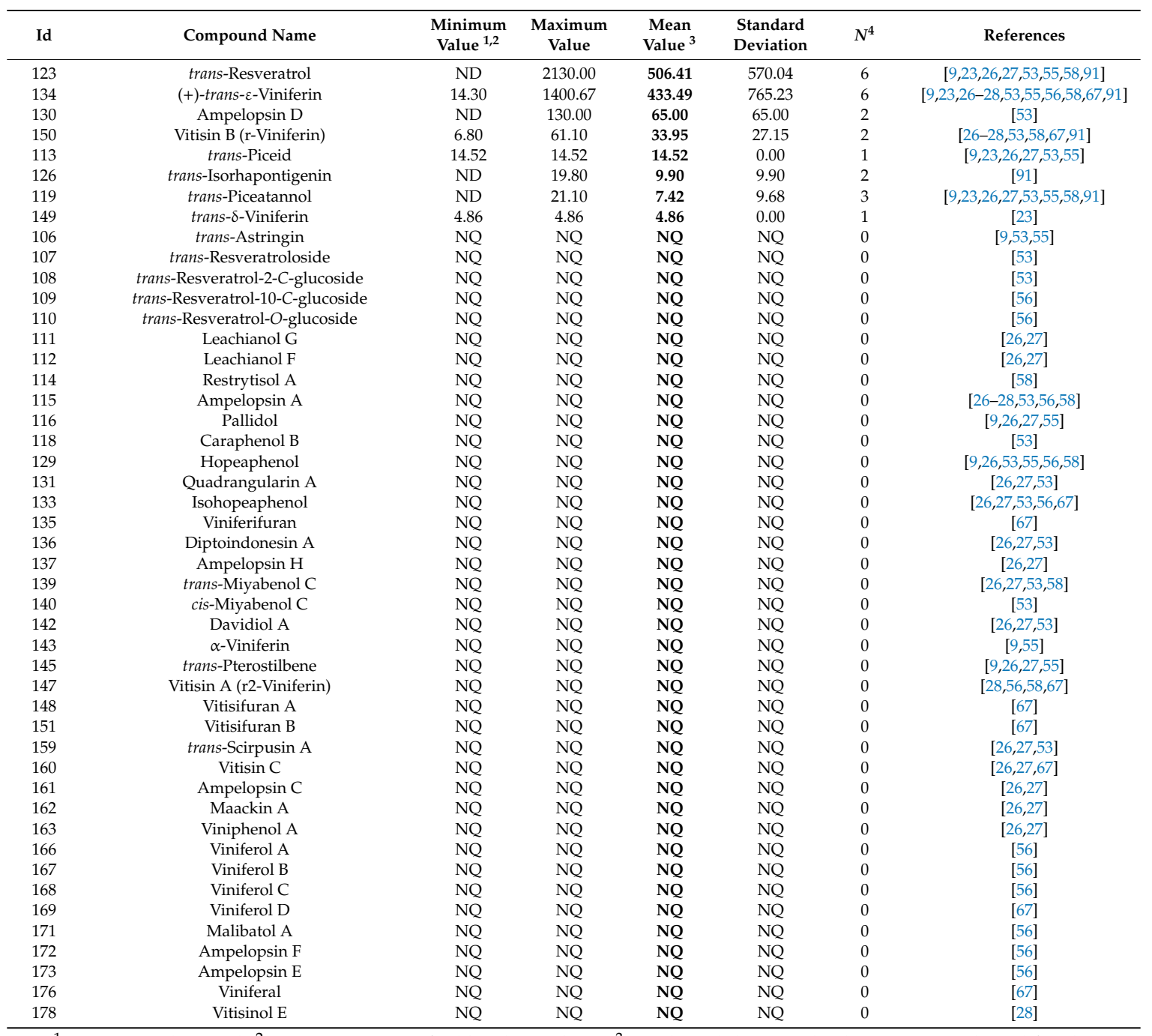

${ }^{1} \mathrm{ND}=$ not detected. ${ }^{2} \mathrm{NQ}=$ not quantified by the authors. ${ }^{3}$ Fresh and dry weight data were combined for the calculations, without any conversion. ${ }^{4} \mathrm{~N}=$ number of data points used in the calculation of the mean value, and made of minimum, maximum, and average values extracted from each reference. 
Table 7. Levels (mg/kg) of 26 stilbenic compounds identified in grapevine canes.

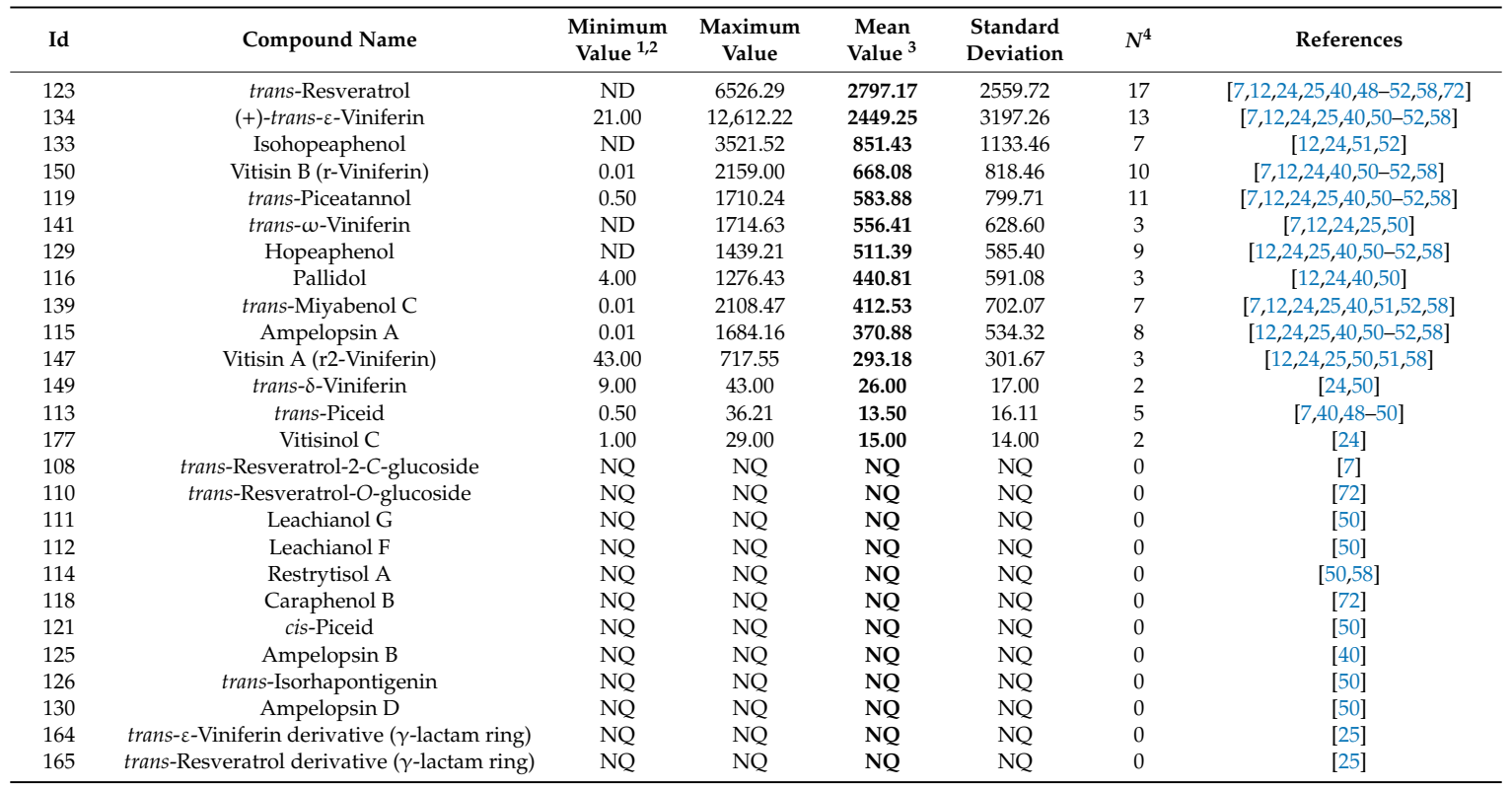

${ }^{1} \mathrm{ND}=$ not detected. ${ }^{2} \mathrm{NQ}=$ not quantified by the authors. ${ }^{3}$ Fresh and dry weight data were combined for the calculations, without any conversion. ${ }^{4} \mathrm{~N}=$ number of data points used in the calculation of the mean value, and made of minimum, maximum, and average values extracted from each reference.

Table 8. Levels $(\mathrm{mg} / \mathrm{kg}$ ) of 23 polyphenols (excluding stilbenes) identified in grapevine canes.

\begin{tabular}{|c|c|c|c|c|c|c|c|}
\hline Id & Compound Name & $\begin{array}{c}\text { Minimum } \\
\text { Value }^{1}\end{array}$ & $\begin{array}{c}\text { Maximum } \\
\text { Value }\end{array}$ & $\begin{array}{c}\text { Mean } \\
\text { Value }^{2}\end{array}$ & $\begin{array}{c}\text { Standard } \\
\text { Deviation }\end{array}$ & $N^{3}$ & References \\
\hline 23 & Catechin & 65.16 & 6735.24 & 1747.01 & 2525.88 & 10 & {$[46,48-50,83]$} \\
\hline 48 & Sinapic acid & 26.41 & 2283.20 & 1154.81 & 1128.40 & 4 & {$[46,47,83]$} \\
\hline 6 & Procyanidin B1 & 215.36 & 806.87 & 511.12 & 295.76 & 2 & {$[50]$} \\
\hline 40 & Epicatechin & 45.53 & 896.17 & 269.40 & 289.87 & 6 & [48-50] \\
\hline 46 & Ferulic acid & 0.92 & 650.13 & 165.63 & 279.74 & 8 & {$[46-49,83]$} \\
\hline 2 & Gallic acid & 7.21 & 570.13 & 165.06 & 234.37 & 8 & {$[46-49,83]$} \\
\hline 38 & Prodelphinidin A-type & 27.46 & 292.88 & 160.17 & 132.71 & 2 & [50] \\
\hline 4 & Protocatechuic acid & 3.25 & 379.85 & 103.31 & 159.84 & 8 & {$[46-49,83]$} \\
\hline 24 & Caftaric acid & 18.64 & 77.60 & 48.12 & 29.48 & 4 & {$[48,49]$} \\
\hline 7 & $p$-Hydroxybenzoic acid & 0.01 & 95.22 & 47.62 & 47.61 & 4 & {$[46,47,83]$} \\
\hline 30 & Vanillic acid & 0.01 & 152.10 & 40.13 & 64.74 & 8 & {$[46-49,83]$} \\
\hline 36 & Syringic acid & 0.01 & 113.09 & 31.05 & 47.43 & 8 & {$[46-49,83]$} \\
\hline 50 & Ellagic acid & 0.01 & 53.25 & 18.78 & 20.99 & 8 & {$[46,48,49,83]$} \\
\hline 27 & Coutaric acid & 5.20 & 19.39 & 12.30 & 7.10 & 4 & {$[48,49]$} \\
\hline 43 & $p$-Coumaric acid & 0.01 & 31.20 & 11.13 & 11.97 & 8 & {$[46-49,83]$} \\
\hline 35 & Caffeic acid & 1.15 & 3.43 & 2.29 & 1.14 & 4 & [47-49] \\
\hline 10 & Procyanidin A1 & NQ & NQ & NQ & NQ & 0 & [50] \\
\hline 18 & Procyanidin C1 & NQ & NQ & NQ & NQ & 0 & {$[50]$} \\
\hline 19 & Procyanidin $\mathrm{T} 2$ & NQ & NQ & NQ & NQ & 0 & [50] \\
\hline 29 & Procyanidin B2 & NQ & NQ & NQ & NQ & 0 & {$[50]$} \\
\hline 39 & Procyanidin dimer gallate & NQ & NQ & NQ & NQ & 0 & {$[50]$} \\
\hline 58 & Quercetin-3-O-galactoside & NQ & NQ & NQ & NQ & 0 & [50] \\
\hline 77 & Quercetin-3-O-arabinose & NQ & NQ & NQ & NQ & 0 & {$[50]$} \\
\hline
\end{tabular}

${ }^{1} \mathrm{NQ}=$ not quantified by the authors. ${ }^{2}$ Fresh and dry weight data were combined for the calculations, without any conversion. ${ }^{3} \mathrm{~N}=$ number of data points used in the calculation of the mean value, and made of minimum, maximum, and average values extracted from each reference. 
Table 9. Levels (mg/kg) of 23 stilbenic compounds identified in grapevine woods.

\begin{tabular}{|c|c|c|c|c|c|c|c|}
\hline Id & Compound Name & $\underset{\text { Value }^{1,2}}{\text { Minimum }}$ & $\begin{array}{l}\text { Maximum } \\
\text { Value }\end{array}$ & $\begin{array}{c}\text { Mean } \\
\text { Value }^{3}\end{array}$ & $\begin{array}{l}\text { Standard } \\
\text { Deviation }\end{array}$ & $N^{4}$ & References \\
\hline 134 & $(+)$-trans- $\varepsilon$-Viniferin & 122.57 & $14,080.88$ & 8263.87 & 4866.89 & 7 & {$[12,13,43,45]$} \\
\hline 132 & $(+)$-cis- $\varepsilon$-Viniferin & 2504.08 & $14,023.65$ & 3851.97 & 5759.79 & 2 & [13] \\
\hline 133 & Isohopeaphenol & 11.68 & 7913.00 & 2429.69 & 2544.59 & 7 & {$[12,13,43,45]$} \\
\hline 143 & $\alpha$-Viniferin & ND & 4732.06 & 2366.03 & 2366.03 & 2 & [13] \\
\hline 123 & trans-Resveratrol & 15.11 & 3604.04 & 2195.12 & 1414.54 & 7 & {$[12,13,43,45]$} \\
\hline 137 & Ampelopsin H & 1144.77 & 2518.08 & 1831.43 & 686.66 & 2 & [13] \\
\hline 116 & Pallidol & 410.60 & 2602.15 & 1647.36 & 916.64 & 3 & {$[12,13]$} \\
\hline 111 & Leachianol G & 350.32 & 2800.34 & 1575.33 & 1225.01 & 2 & [13] \\
\hline 129 & Hopeaphenol & 20.09 & 5006.77 & 1570.13 & 1683.09 & 7 & {$[12,13,43,45]$} \\
\hline 141 & trans- $\omega$-Viniferin & 1554.16 & 1554.16 & 1554.16 & 0.00 & 1 & [12] \\
\hline 112 & Leachianol F & 35.57 & 2805.13 & 1420.35 & 1384.78 & 2 & [13] \\
\hline 115 & Ampelopsin A & 151.00 & 3684.01 & 1345.17 & 1541.97 & 5 & {$[12,13,45]$} \\
\hline 147 & Vitisin A (r2-Viniferin) & 1298.67 & 1298.67 & 1298.67 & 0.00 & 1 & [12] \\
\hline 128 & cis-Resveratrol & 780.58 & 3609.66 & 774.64 & 1192.86 & 2 & [13] \\
\hline 110 & trans-Resveratrol-O-glucoside & e 131.00 & 1090.00 & 610.50 & 479.50 & 2 & [44] \\
\hline 150 & Vitisin B (r-Viniferin) & 569.18 & 569.18 & 569.18 & 0.00 & 1 & [12] \\
\hline 139 & trans-Miyabenol C & ND & 1339.51 & 430.02 & 482.17 & 5 & {$[12,13,45]$} \\
\hline 125 & Ampelopsin B & ND & 493.44 & 246.72 & 246.72 & 2 & [13] \\
\hline 119 & trans-Piceatannol & 38.00 & 378.07 & 160.69 & 154.14 & 3 & {$[12,45]$} \\
\hline 130 & Ampelopsin D & 10.51 & 310.22 & 160.37 & 149.86 & 2 & [43] \\
\hline 113 & trans-Piceid & 35.00 & 50.00 & 42.50 & 7.50 & 2 & [45] \\
\hline 136 & Diptoindonesin A & 9.78 & 57.70 & 33.74 & 23.96 & 2 & [44] \\
\hline 106 & trans-Astringin & 2.56 & 24.00 & 13.28 & 10.72 & 2 & [44] \\
\hline
\end{tabular}

${ }^{1} \mathrm{ND}=$ not detected. ${ }^{2} \mathrm{NQ}=$ not quantified by the authors. ${ }^{3}$ Fresh and dry weight data were combined for the calculations, without any conversion. ${ }^{4} N=$ number of data points used in the calculation of the mean value, and made of minimum, maximum, and average values extracted from each reference.

Table 10. Levels $(\mathrm{mg} / \mathrm{kg})$ of 24 stilbenic compounds identified in grapevine roots.

\begin{tabular}{|c|c|c|c|c|c|c|c|}
\hline Id & Compound Name & $\begin{array}{c}\text { Minimum } \\
\text { Value }\end{array}$ & $\begin{array}{l}\text { Maximum } \\
\text { Value }\end{array}$ & $\begin{array}{c}\text { Mean } \\
\text { Value }^{2}\end{array}$ & $\begin{array}{l}\text { Standard } \\
\text { Deviation }\end{array}$ & $N^{3}$ & References \\
\hline 134 & $(+)$-trans- $\varepsilon$-Viniferin & 125.10 & $18,000.98$ & 6475.95 & 8163.57 & 3 & {$[12,23,30,43]$} \\
\hline 150 & Vitisin B (r-Viniferin) & 11.10 & $12,829.85$ & 6420.48 & 6409.38 & 2 & {$[12,30,41,42]$} \\
\hline 129 & Hopeaphenol & 1814.90 & 1814.90 & 1814.90 & 0.00 & 1 & {$[12,41,42]$} \\
\hline 115 & Ampelopsin A & 15.60 & 2178.23 & 1096.92 & 1081.32 & 2 & {$[12,29,30,41,42]$} \\
\hline 147 & Vitisin A (r2-viniferin) & 87.10 & 2093.13 & 1090.12 & 1003.02 & 2 & {$[12,30]$} \\
\hline 133 & Isohopeaphenol & 529.54 & 529.54 & 529.54 & 0.00 & 1 & [12] \\
\hline 123 & trans-Resveratrol & 46.30 & 1095.24 & 503.25 & 438.74 & 3 & {$[12,23,29,30]$} \\
\hline 141 & trans- $\omega$-Viniferin & 127.70 & 127.70 & 127.70 & 0.00 & 1 & [12] \\
\hline 139 & trans-Miyabenol C & 12.70 & 212.34 & 112.52 & 99.82 & 2 & {$[12,30]$} \\
\hline 113 & trans-Piceid & 112.07 & 112.07 & 112.07 & 0.00 & 1 & {$[23,29]$} \\
\hline 116 & Pallidol & 73.06 & 73.06 & 73.06 & 0.00 & 1 & {$[12,29]$} \\
\hline 119 & trans-Piceatannol & 4.20 & 121.33 & 47.18 & 52.66 & 3 & {$[12,23,30]$} \\
\hline 149 & trans- $\delta$-viniferin & 32.77 & 32.77 & 32.77 & 0.00 & 1 & [23] \\
\hline 121 & cis-Piceid & NQ & NQ & NQ & NQ & 0 & [29] \\
\hline 161 & Ampelopsin C & NQ & NQ & NQ & NQ & 0 & {$[41,42]$} \\
\hline 169 & Viniferol D & NQ & NQ & NQ & NQ & 0 & {$[41,42]$} \\
\hline 170 & Viniferol E & NQ & NQ & NQ & NQ & 0 & {$[41,42]$} \\
\hline 173 & Ampelopsin E & NQ & NQ & NQ & NQ & 0 & {$[41,42]$} \\
\hline 174 & Wilsonol C & NQ & NQ & NQ & NQ & 0 & [29] \\
\hline 175 & Heyneanol A & NQ & NQ & NQ & NQ & 0 & [29] \\
\hline 179 & Vitisinol B & NQ & NQ & NQ & NQ & 0 & {$[41,42]$} \\
\hline 180 & Stenophyllol C & NQ & NQ & NQ & NQ & 0 & {$[41,42]$} \\
\hline 181 & Viniferether A & NQ & NQ & NQ & NQ & 0 & {$[41,42]$} \\
\hline 182 & Viniferether B & NQ & NQ & NQ & NQ & 0 & {$[41,42]$} \\
\hline
\end{tabular}

${ }^{1} \mathrm{NQ}=$ not quantified by the authors. ${ }^{2}$ Fresh and dry weight data were combined for the calculations, without any conversion. ${ }^{3} \mathrm{~N}=$ number of data points used in the calculation of the mean value, and made of minimum, maximum, and average values extracted from each reference.

\subsection{Phenolic Compounds in Grapevine Canes}

Compared to leaves and stems, fewer studies have been conducted on the phenolic composition of grapevine canes, which explains the report of only 49 phenolic compounds for the organ. These data indicate that canes have substantial quantities of valuable health-promoting stilbenes $[7,12,40,46,51,52,58]$. Compounds usually present in the cane extracts Table 7) are trans-resveratrol $(2797.17 \mathrm{mg} / \mathrm{kg})$, (+)-trans- $\varepsilon$-viniferin $(2449.25 \mathrm{mg} / \mathrm{kg})$, isohopeaphenol $(851.43 \mathrm{mg} / \mathrm{kg})$, 
vitisin B $(668.08 \mathrm{mg} / \mathrm{kg})$, trans-piceatannol $(583.88 \mathrm{mg} / \mathrm{kg})$, trans- $\omega$-viniferin $(556.41 \mathrm{mg} / \mathrm{kg})$, and hopeaphenol (511.39 mg/kg); the remaining compounds are with levels below $500 \mathrm{mg} / \mathrm{kg}$.

Other compounds identified in the canes with significant amounts are catechin $(1747.01 \mathrm{mg} / \mathrm{kg})$, sinapic acid (1154.81 mg/kg), procyanidin B1 (511.12 mg/kg), epicatechin $(269.40 \mathrm{mg} / \mathrm{kg})$, ferulic acid $(165.63 \mathrm{mg} / \mathrm{kg})$, gallic acid $(165.06 \mathrm{mg} / \mathrm{kg})$, prodelphinidin A-type $(160.17 \mathrm{mg} / \mathrm{kg})$, and protocatechuic acid $(103.31 \mathrm{mg} / \mathrm{kg}$ ) (Table 8$)$. Ferulic acid, for example, has been reported as the major compound in the shoots of various grapevine cultivars $[47,83]$.

\subsection{Phenolic Compounds in Grapevine Woods}

No report was found related to the identification of phenolic acids and flavonoids in the woods (trunk and cordons) of the vine plant. All the 23 stilbenes identified in the woods of various cultivars have been quantified, as shown in Table 9, and with generally high levels ranging from $13.28 \mathrm{mg} / \mathrm{kg}$ for trans-astringin to $8263.87 \mathrm{mg} / \mathrm{kg}$ for (+)-trans- $\varepsilon$-viniferin [12,13]. The most abundant compounds are (+)-trans- $\varepsilon$-viniferin $(8263.87 \mathrm{mg} / \mathrm{kg}),(+)$-cis- $\varepsilon$-viniferin $(3851.97 \mathrm{mg} / \mathrm{kg})$, isohopeaphenol $(2429.69 \mathrm{mg} / \mathrm{kg}), \alpha$-viniferin $(2366.03 \mathrm{mg} / \mathrm{kg})$, and trans-resveratrol $(2195.12 \mathrm{mg} / \mathrm{kg})$. Eight compounds are with levels between 1000 and $2000 \mathrm{mg} / \mathrm{kg}$, seven with levels between 100 and $1000 \mathrm{mg} / \mathrm{kg}$, and three with levels between 10 and $50 \mathrm{mg} / \mathrm{kg}$.

\subsection{Phenolic Compounds in Grapevine Roots}

As with the woods, there are no reports on the phenolic acid and flavonoid profiles of grapevine roots. The 24 stilbenes in the roots $[12,30,41,42,62]$ can be ranked, on the basis of abundance, in the

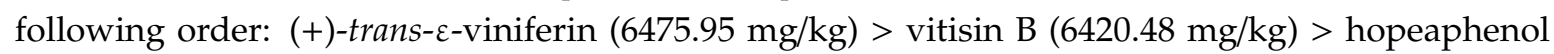
$(1814.90 \mathrm{mg} / \mathrm{kg})>$ ampelopsin A $(1096.92 \mathrm{mg} / \mathrm{kg})>$ vitisin A $(1090.12 \mathrm{mg} / \mathrm{kg})>$ isohopeaphenol $(529.54 \mathrm{mg} / \mathrm{kg})>$ trans-resveratrol $(503.25 \mathrm{mg} / \mathrm{kg})($ Table 10$)$.

\section{Distribution of Phenolic Compounds in the Vegetative Organs of Grapevine}

A mapping of the distribution of phenolic compounds in grapevine shows that composition and levels greatly vary according to the organ investigated (Figures 1 and 2). In general, flavonoids constitute the largest group of phenolics. From an anatomical point of view, these compounds localize specifically in the stems, with lower amounts in the leaves and the canes (Figure 1).

The overall data obtained through adding together the available individual compound means (not shown) indicate that the total amount of phenolics in the stems is on average $114,415.68 \mathrm{mg} / \mathrm{kg}$. Flavan-3-ols constitute the most abundant group of compounds in the stems (61.63\%; catechin, epicatechin, and procyanidin B1 with the highest levels), followed by flavonols (23.75\%; quercetin-3-O-galactoside with the highest level), hydroxybenzoic acids $(9.03 \%$ with a high abundance of gallic acid), hydroxycinnamic acids (3.66\%), anthocyanins $(0.99 \%)$, and stilbenes $(0.94 \%)$. From an industrial point of view, stems seem to be an important source of proanthocyanidins for potential use as nutraceutical, enological products, chemical standards, or even in winemaking to regulate the composition of flavonoids in wine [69].

Flavonols are quantitatively the most abundant phenolic class in the leaves $(83.43 \%$ of the total amount of phenolics, i.e., $37,052.70 \mathrm{mg} / \mathrm{kg}$ ) with a high abundance of quercetin-3-O-glucuronide, quercetin-3-O-galactoside, and quercetin-3-O-glucoside; flavonols are followed by hydroxycinnamic acids $(13.19 \%$, of which caftaric acid and coutaric acid have the highest levels), stilbenes $(2.63 \%)$, flavan-3-ols $(0.41 \%)$, and hydroxybenzoic acids $(0.26 \%)$. Coumarins, flavones, anthocyanins, and flavanones are found in minor amounts. The spatial distribution of phenolic compounds in grapevine leaves evaluated by matrix-assisted laser desorption/ionization (MALDI) showed the specific colocation of trans-resveratrol, pterostilbene, and viniferins around the veins in healthy leaves [68]. It is reported that the leaf blade is more abundant in phenolic compounds than the petiole, and much less than the pedicel $[75,84]$. 
There are very few reports on flavonols, flavones, flavanones, anthocyanins, and coumarins in the canes. Phenolic groups identified (on average 14,477.42 mg/kg) can be classified in terms of abundance as stilbenes $(69.00 \%$ of the total) $>$ flavan-3-ols $(18.56 \%$; catechin, procyanidin B1 and epicatechin with the highest levels as with the stems) $>$ hydroxycinnamic acids $(9.63 \%$ of which sinapic acid and ferulic acid) $>$ hydroxybenzoic acids (2.80\% of which gallic acid). Indeed, in the comparison of phenolics in the skins, pulps, seeds, canes, and leaves of six cultivars grown in Iran, it was found that the canes usually contained the highest amounts of flavonoids and stilbenes [87].
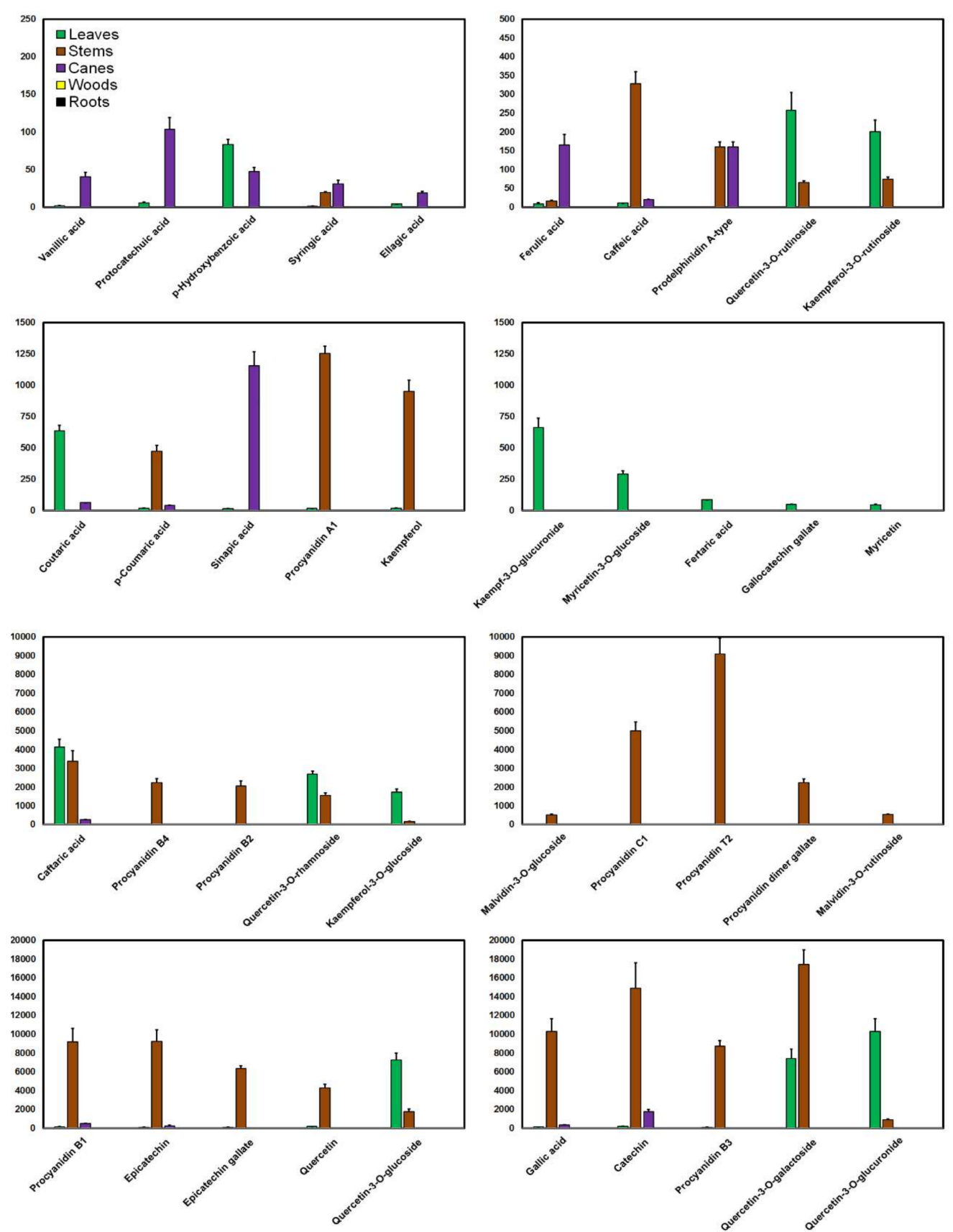

Figure 1. Distribution of the major phenolic acids and flavonoids in the vegetative organs of the vine plant: mean values ( $y$-axis; $\mathrm{mg} / \mathrm{kg}$ ) + standard deviations as error bars divided by 10 for better visualization. 

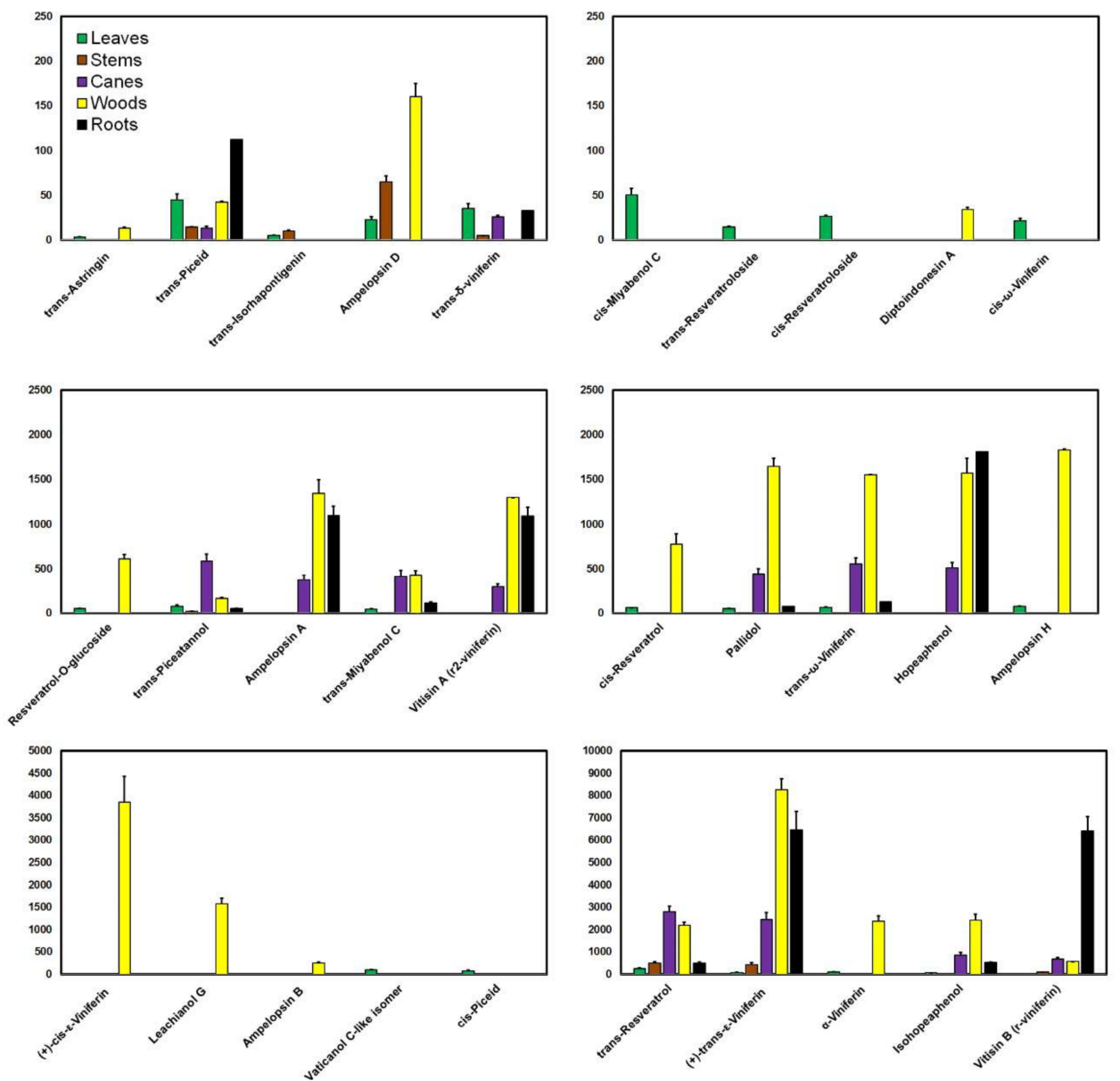

Figure 2. Distribution of the major stilbenic compounds in the vegetative organs of the vine plant: mean values ( $y$-axis; $\mathrm{mg} / \mathrm{kg}$ ) + standard deviations as error bars divided by 10 for better visualization.

The data also show that stilbenes accumulate primarily in the woods $(34,390.90 \mathrm{mg} / \mathrm{kg}$; $\varepsilon$-viniferin, isohopeaphenol, trans-resveratrol, $\alpha$-viniferin, and ampelopsin $\mathrm{H}$ with the highest levels), followed by the roots (18436.44 mg/kg; $\varepsilon$-viniferin, hopeaphenol, vitisin B, and ampelopsin A with the highest levels), the canes $(9989.50 \mathrm{mg} / \mathrm{kg}$; $\varepsilon$-viniferin, trans-resveratrol, isohopeaphenol, vitisin $\mathrm{B}$, and trans-piceatannol with the highest levels), and the stems $(1075.55 \mathrm{mg} / \mathrm{kg}$; $\varepsilon$-viniferin, trans-resveratrol, vitisin $\mathrm{B}$, and ampelopsin D with the highest levels), whereas leaves, which are more exposed to environmental stresses [23,40], have a low concentration of these compounds $(972.97 \mathrm{mg} / \mathrm{kg}$; trans-resveratrol, vaticanol C-like isomer, piceid, trans-piceatannol, and ampelopsin $\mathrm{H}$ with the highest levels) (Figure 2).

Stilbenes are more constitutively expressed in the woods, roots, canes, and stems, where they are believed to help in the prevention of wood rot $[12,39,62]$. This constitutive expression might explain the more consistent and greater levels of compounds in these plant parts, in contrast to the leaves in which stilbene production is mostly induced to provide enhanced protection against pests and diseases $[12,23,65,85]$. Levels of stilbenes were compared in the wood, roots, and canes by [12]; grapevine canes usually had $\varepsilon$-viniferin and trans-resveratrol as their main compounds, and woods had more $\varepsilon$-viniferin and isohopeaphenol, whereas roots were generally rich in vitisin $B$, ampelopsin $\mathrm{A}$, and vitisin A [12]. The authors concluded that the degree of oligomerization of stilbenes increases from the aerial organs to the root system. After manual dissection of the cortex, pith, and conducting tissues of grape canes, the evaluation of the spatial distribution of stilbenes suggested a predominance of monomers in conducting tissues and oligomers in cortex and pith [52]. 


\section{Factors Affecting the Biosynthesis and Levels of Phenolic Compounds in the Vegetative Organs of Grapevine}

Grapevine phenolics occur in large concentration ranges, as attested by standard deviation values presented in Tables 3-10. There are a number of factors that interact together, so as to result in such wide range of phenolic variations. Some of these factors are well documented in the literature and include cultivars, climate, cultural practices, and biotic and abiotic stresses.

\subsection{Grapevine Cultivars and Rootstocks}

Grapevine cultivars are not genetically homogeneous, and most of them are multiplied by vegetative propagation. A collection of vines propagated from the same mother vine make up a clone; clonal selection is routinely carried out in viticulture with the purpose of creating disease-free or high-yielding populations. Progressively, criteria such as the levels of grape sugar and skin phenolic compounds have been integrated in clonal selection programs. Moreover, these clones are often grafted on different rootstocks $[2,9,90]$. These factors could explain why the contents of polyphenols are subject to such severe variations $[6,32,58,59,89]$. For instance, plants of Pinot blanc grafted on three different rootstocks-Kober 5B, S04, and 1103P-accumulated resveratrol differentially in the leaves [14]. According to some authors, the best resveratrol-producing cultivars are Pinot noir and Cabernet Sauvignon, depending on the clones investigated [5,6,51]. A comparison of the phenolic profile of canes of the cultivars Chardonnay, Cabernet Sauvignon, Shiraz (Syrah), Merlot, Sauvignon blanc, and Pinot noir showed that Pinot noir had very high levels of trans-resveratrol

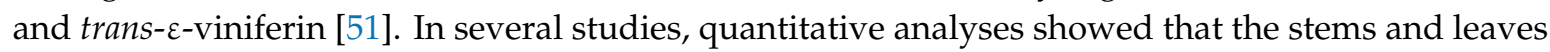
of red cultivars are richer in proanthocyanidins, flavonols, hydroxycinnamic acids, anthocyanins, and stilbenes than those of white cultivars [33,53,54,91]. The biosynthesis of phenolic compounds is also closely dependent on plant developmental stages. It has indeed been reported that very young and very old leaves do not synthesize high stilbene and anthocyanin levels, probably because of the incomplete development of the stomata $[9,69,77,79,84]$. In the study by [89], however, the intensity of stilbene induction did not show a clear and homogeneous correlation with the position of leaves along the shoot. The total viniferin content was generally highest in the second, third, and fourth leaves for the 21/103 genotype. Moreover, [25] did not find a homogeneous trend of change in stilbenoid levels in the stems during the growth cycle.

\subsection{Geographical Location and Climate (Shading, Temperature, Irrigation)}

The geographical location of the vineyard (especially latitude and elevation) and the seasonal meteorological variability in the area are known to influence the phenolic composition of grapevine organs. Meteorological variability, including light, temperature, and water, represents one of the main environmental factors responsible for phenolic biosynthesis. Clear separation was demonstrated between the phenolic profile of leaves $[32,79,86]$ and stems [40] of grapevine cultivars of different geographical origins. A higher variation of stilbene levels between years as compared to variation between plants of the same year have also been reported [89]. Different light exposures of the vine demonstrated that shading decreases the flavonoid content of the leaves, a result that is consistent with the role these molecules play in protecting tissues from UV light $[85,91]$. In the study by [59], accumulation of quercetin-3-O-glucoside, kaempferol-3-O-glucoside, and quercetin-3-O-galactoside was the most prominent in full sunlight-exposed leaves compared with half-shaded leaves. Furthermore, the biosynthesis of phenolics is sensitive to diurnal differences in temperature, although with different temporal patterns. Indeed, a decrease of flavonoid biosynthesis has been observed when the temperature is limiting or excessive [92]. Extreme weather conditions with prolonged dry periods as well as heavy rain events can severely influence grapevine physiology $[2,86]$. Water deficit has been reported to upregulate the expression of genes of the anthocyanin pathway [77] and to increase the levels of most polyphenols in the leaves, in particular cis-resveratrol-3-O-glucoside, kaempferol-3-O-glucoside, and quercetin-3-O-glucoside [60]. Recent results show that, during water stress, the synthesis of 
anthocyanins is paralleled by an increase of the expression of flavonoid transporters [65]. On the other hand, it is reported that excessive water application could induce a decrease in proanthocyanidin levels [92].

\subsection{Vinicultural Practices}

There are many cultural practices that affect the production and accumulation of phenolic compounds in grapevine organs. However, many of these factors seem to act in a typical bell-shaped manner, where they could improve the final levels of compounds only when present at optimal levels. For instance, pruning greatly influences the levels of stilbenoids in the canes, leaves, and stems of grapevine, but the effect depends on the number of branches removed and the duration of the treatment $[40,50]$. In canes remaining on the plant 30 days after pruning, only a minor increase of total stilbenoid levels was observed, whereas in canes stored at room temperature after pruning, a twofold increase occurred [40]. In general, practices that increase plant vigor, such as fertilizer application, are reported to negatively influence the biosynthesis of phenolics in grapevine. Less trans-resveratrol was accumulated in the leaves when increasing nitrogen doses were applied to one-year-old potted vines, whereas the opposite was observed with increased potassium doses; when nitrogen and potassium were supplied together, potassium did not balance the negative effect of nitrogen [14]. Iron deficiency stimulated anthocyanin accumulation in grapevine apical leaves [78]. The application of other agrochemicals (e.g., plant hormones and chitosan) with the aim of enhancing vegetative growth and grape quality also affects phenolic biosynthesis in a complex way [18]. Typically, it has been reported that abscisic, auxin, and ethylene application lead to an increase in the levels of flavonoids, whereas the opposite has been observed with the application of gibberellic acid and inhibitors of the ethylene receptor [65]. Indirectly, fertilizer and hormone application could also lead to low levels of polyphenols because they induce the production of especially dense foliage that limits the exposure of some organs to sunlight. Grapevine is susceptible to various pests and diseases usually controlled by chemical and biological treatments that can introduce additional variability in the data. High amounts of stilbenoids were produced in grapevine plants that were mycorrhized with Rhizophagus irregularis, as well as an up-regulation in the leaves of genes involved in the stilbene biosynthesis pathway [70].

\subsection{Outside and Biotic Stimuli}

High variability in phenolic levels in grapevine is best explained by biotic stresses and mechanical injuries. In most studies, it was found that the infection status of the plant influences phenolic profiles much more than other factors [9]. Indeed, following pathogen attacks and insect bites, all the vegetative organs of grapevine undergo modifications in terms of their polyphenol composition and contents. For phenolic acids, flavonoids, and coumarins, the literature is contradictory regarding the relationship between level and disease susceptibility [15]. This might be due to the fact that these compounds are part of the constitutive metabolome in lignified tissues. In the study by [77], the expression of flavonoid pathway genes was detected in both healthy and diseased leaves, confirming that the pathway is active in control conditions [77]. These polyphenols that are present prior to an attempted infection of the plant are known as preformed, and are part of a passive resistance mechanism $[14,36]$. A mechanism of active resistance is the synthesis, degradation, or metabolism to a different compound in response to attacks by pathogens; de novo synthesized compounds are called phytoalexins [71]. An induction in the synthesis of stilbenic compounds in photosynthetic tissues has been considerately reported in response to the main grapevine pathogens, namely, Botrytis cinerea of grey mould [70], Plasmopara viticola of downy mildew $[6,10,12,52,61,62,64,68,70,73,82,89]$, Erysiphe necator of powdery mildew $[11,88]$, fungi associated with grapevine trunk diseases $[3,13,15,43-45,86]$, Rhizopus stolonifera of berry rot [14], Grapevine leafroll-associated virus 3 of Grapevine leafroll disease [77], Xylella fastidiosa of Pierce's disease [9,55], and Aspergillus carbonarius of sour rot [71]. The increment can be as high as 100-fold, and has a biosynthetic origin attributable to stilbene synthase induction. Interestingly, it was found that downy mildew affects the spatial repartition of stilbenoids in the cane, with an increase in 
the cortex (a tissue notably involved in protection against mechanical damage and microbial attack) and conducting tissues, and a decrease in the pith [52]. Mechanical stress on freshly pruned canes and leaves have also been reported to overinduce the biosynthesis of trans-resveratrol and trans-piceatannol within a short period after pruning $[23,40]$.

\section{Concluding Remarks}

Several compounds with phenolic characteristic have been detected in the leaves, stems, canes, woods, and roots of the grapevine plant. An effort is still needed to identify and quantify several of these compounds. It is clear that several factors affect the biosynthetic pathways, leading to the accumulation of phenolic compounds in grapevine. The patterns of gene expression show significant differences between organs and cultivars, especially for genes involved in stilbene synthesis. In the leaves in particular, random inductions in the synthesis of these compounds have been observed, which is understandable given their higher exposure to the environment and resulting susceptibility to attack by pests and diseases. An understanding of the different roles of these factors is crucial because only with this information will it be possible to develop cultural practices aimed at improving phenolic levels in the plants and in the derived products. Moreover, unexplored areas of research related to this topic will most certainly constitute a basis for future improvement of grapevine disease tolerance.

Supplementary Materials: The following are available online at http://www.mdpi.com/2076-3921/9/5/398/s1, Table S1: Reference source for phenolic acids, flavonoids and coumarins identified in the vegetative organs of grapevine (Vitis vinifera L.). Table S2: Reference source for stilbenes identified in the vegetative organs of grapevine (Vitis vinifera L.).

Author Contributions: Conceptualization, P.G. and I.C.; methodology, P.G. and R.K.S.; software, P.G.; validation, P.G., I.C., and R.K.S.; formal analysis, P.G.; investigation, P.G. and R.K.S.; resources, I.C.; data curation, P.G. and R.K.S.; writing - original draft preparation, P.G.; writing - review and editing, P.G., I.C., and R.K.S.; visualization, P.G.; supervision, I.C.; project administration, I.C.; funding acquisition, I.C. All authors have read and agreed to the published version of the manuscript.

Funding: This research was funded by the R\&D project "INNOVINE \& WINE -Vineyard and Wine Innovation Platform (NORTE-01-0145-FEDER-000038)", co-supported by Fundo Europeu de Desenvolvimento Regional (FEDER) and Norte 2020 (Programa Operacional Regional do Norte 2014/2020), project UIDB/04033/2020 supported by FCT-Fundação para a Ciência e a Tecnologia.

Conflicts of Interest: The authors declare no conflict of interest. The funders had no role in the design of the study; in the collection, analyses, or interpretation of data; in the writing of the manuscript; or in the decision to publish the results.

\section{References}

1. Hmamouchi, M.; Es-Safi, N.; Lahrichi, M.; Fruchier, A.; Essassi, E.M. Flavones and flavonols in leaves of some Moroccan Vitis vinifera cultivars. Am. J. Enol. Viticult. 1996, 47, 186-192.

2. Harb, J.; Alseekh, S.; Tohge, T.; Fernie, R.A. Profiling of primary metabolites and flavonols in leaves of two table grape varieties collected from semiarid and temperate regions. Phytochemistry 2015, 117, 444-455. [CrossRef] [PubMed]

3. Lima, R.M.M.; Felgueiras, M.L.; Cunh, A.; Chicau, G.; Ferreres, F.; Dias, C.P.A. Differential phenolic production in leaves of Vitis vinifera cv. Alvarinho affected with esca disease. Plant Physiol. Biochem. 2017, 112, 45-52. [CrossRef]

4. Handoussa, H.; Hanafi, R.; El-Khatib, A.; Linscheid, M.; Mahran, L.; Ayoub, N. Computer-assisted HPLC method development using DryLab for determination of major phenolic components in Corchorus olitorius and Vitis vinifera by using HPLC-PDA-ESI-TOF- MSn . Res. Rev. J. Bot. Sci. 2017, 6, 9-16.

5. Dresch, R.R.; Dresch, K.M.; Guerreiro, F.A.; Biegelmeyer, R.; Holzschuh, M.H.; Rambo, F.D.; Henriques, T.A. Phenolic compounds from the leaves of Vitis labrusca and Vitis vinifera L. as a source of waste byproducts: Development and validation of LC method and antichemotactic activity. Food Anal. Methods 2014, 7, 527-539. [CrossRef] 
6. Leeuwen, V.C.; Roby, J.P.; Villaverde, A.V.; Gindro, K. Impact of clonal variability in Vitis vinifera cabernet franc on grape composition, wine quality, leaf blade stilbene content, and downy mildew resistance. J. Agric. Food Chem. 2013, 61, 19-24. [CrossRef]

7. Pawlus, D.A.; Sahli, R.; Bisson, J.; Rivière, C.; Delaunay, J.C.; Richard, T.; Gomès, E.; Bordenave, L.; Waffo-Téguo, P.; Mérillon, J.M. Stilbenoid profiles of canes from Vitis and Muscadinia species. J. Agric. Food Chem. 2013, 61, 501-511. [CrossRef] [PubMed]

8. Pawlus, D.A.; Waffo-Téguo, P.; Shaver, J.; Mérillon, J.M. Stilbenoid chemistry from wine and the genus vitis, a review. J. Int. Sci. Vigne. Vin. 2012, 46, 57-111. [CrossRef]

9. Wallis, M.C.; Wallingford, K.A.; Chen, J.C. Effects of cultivar, phenology, and Xylella fastidiosa infection on grapevine xylem sap and tissue phenolic content. Physiol. Mol. Plant Pathol. 2013, 84, 28-35. [CrossRef]

10. Jean-Denis, J.B.; Pezet, R.; Tabacchi, R. Rapid analysis of stilbenes and derivatives from downy mildew-infected grapevine leaves by liquid chromatography-atmospheric pressure photoionisation mass spectrometry. J. Chromatogr. A 2006, 1112, 263-268. [CrossRef]

11. Schnee, S.; Viret, O.; Gindro, K. Role of stilbenes in the resistance of grapevine to powdery mildew. Physiol. Mol. Plant Pathol. 2008, 72, 128-133. [CrossRef]

12. Gabaston, J.; Villar, C.E.; Biais, B.; Teguo, W.P.; Renouf, E.; Corio-Costet, M.F.; Richard, T.; Mérillon, J.M. Stilbenes from Vitis vinifera L. waste: A sustainable tool for controlling Plasmopara Viticola. J. Agric. Food Chem. 2017, 65, 2711-2718. [CrossRef] [PubMed]

13. Amalfitano, C.; Agrelli, D.; Arrigo, A.; Mugnai, L.; Surico, G.; Evidente, A. Stilbene polyphenols in the brown red wood of Vitis vinifera cv. Sangiovese affected by "esca proper". Phytopathol. Mediterr. 2011, 50, S224-S235.

14. Bavaresco, L.; Fregoni, C. Physiological role and molecular aspects of grapevine stilbenic compounds. In Molecular Biology \& Biotechnology of the Grapevine, Chapter 5, 1st ed.; Roubelakis-Angelakis, K.A., Ed.; Kluwer Academic Publishers: Berlin, Germany, 2001; pp. 153-182.

15. Goufo, P.; Marques, C.A.; Cortez, I. Exhibition of local but not systemic induced phenolic defenses in Vitis vinifera L. affected by brown wood streaking, grapevine leaf stripe, and apoplexy (Esca complex). Plants 2019, 8, 412. [CrossRef]

16. Flamini, R.; De Rosso, M. High-resolution mass spectrometry and biological properties of grapevine and wine stilbenoids. In Studies in Natural Products Chemistry; Chapter 5; Rahman, A., Ed.; Elsevier B.V.: Amsterdam, The Netherlands, 2018; Volume 61, pp. 175-210.

17. Gomès, E.; Coutos-Thévenot, P. Molecular aspects of grapevine-pathogenic fungi interactions. In Grapevine Molecular Physiology E Biotechnology, 2nd ed.; Chapter 15; Roubelakis-Angelakis, K.A., Ed.; Springer Science \& Business Media B.V.: Dordrecht, The Netherlands, 2009; pp. 407-428.

18. Singh, K.R.; Soares, B.; Goufo, P.; Castro, I.; Cosme, F.; Pinto-Sintra, L.A.; Inês, A.; Oliveira, A.A.; Falco, V. Chitosan upregulates the genes of the ROS pathway and enhances the antioxidant potential of grape (Vitis vinifera L. 'Touriga Franca' and 'Tinto Cão') tissues. Antioxidants 2019, 8, 525. [CrossRef] [PubMed]

19. Aouey, B.; Samet, M.A.; Fetoui, H.; Simmonds, S.J.M.; Bouaziz, M. Anti-oxidant, anti-inflammatory, analgesic and antipyretic activities of grapevine leaf extract (Vitis vinifera) in mice and identification of its active constituents by LC-MS/MS analyses. Biomed. Pharmacother. 2016, 84, 1088-1098. [CrossRef]

20. Fernandes, F.; Ramalhosa, E.; Verdial, J.; Valentao, P.; Andrade, P.; Bento, A.; Pereira, A.J. Vitis vinifera leaves towards bioactivity. Ind. Crops Prod. 2015, 43, 434-440. [CrossRef]

21. Apostolou, A.; Stagos, D.; Galitsiou, E.; Spyrou, A.; Haroutounian, S.; Portesis, N.; Trizoglou, I.; Hayes, A.W.; Tsatsakis, M.A.; Kouretas, D. Assessment of polyphenolic content, antioxidant activity, protection against ROS-induced DNA damage and anticancer activity of Vitis vinifera stem extracts. Food Chem. Toxicol. 2013, 61,60-68. [CrossRef]

22. Ramalhosa, E.; Valentão, P.; Andrade, P.; Verdial, J.; Bentoa, A.; Pereira, A.J. Phenolic composition and antioxidant potential of Vitis vinifera leaves of six varieties harvested in northeast of Portugal. FaBE Food Biosyst. Eng. 2013, 2, 169-176.

23. Wei, Y.J.; Zhao, S.R.; Li, J.M.; Xue, B. Stilbene profiles in different tissues of Vitis vinifera L. cv. Cabernet Sauvignon and a comparison of their antioxidant activity. Aust. J. Grape wine Res. 2016, 22, $226-231$. [CrossRef]

24. Biais, B.; Krisa, S.; Cluzet, S.; Da Costa, G.; Waffo-Téguo, P.; Mérillon, J.M.; Richard, T. Antioxidant and cytoprotective activities of grapevine stilbenes. J. Agric. Food Chem. 2017, 65, 4952-4960. [CrossRef] [PubMed] 
25. Macke, S.; Jerz, G.; Empl, T.M.; Steinberg, P.; Winterhalter, P. Activity-guided isolation of resveratrol oligomers from a grapevine-shoot extract using counter current chromatography. J. Agric. Food Chem. 2012, 60, 11919-11927. [CrossRef] [PubMed]

26. Papastamoulis, Y.; Richard, T.; Nassra, M.; Badoc, A.; Krisa, S.; Harakat, D.; Monti, J.P.; Mérillon, J.M.; Téguo, W.P. Viniphenol A, a complex resveratrol hexamer from Vitis vinifera stalks: Structural elucidation and protective effects against amyloid- $\beta$-induced toxicity in PC12 cells. J. Nat. Prod. 2014, 77, 213-217. [CrossRef] [PubMed]

27. Pflieger, A.; Waffo-Téguo, P.; Papastamoulis, Y.; Chaignepain, S.; Subra, F.; Munir, S.; Delelis, O.; Lesbats, P.; Calmels, C.; Andreola, M.L.; et al. Natural stilbenoids isolated from grapevine exhibiting inhibitory effects against HIV-1 integrase and eukaryote MOS1 transposase in vitro activities. PLoS ONE 2013, 8, e81184. [CrossRef]

28. Choi, Y.H.; Yoo, M.Y.; Choi, C.W.; Cha, M.R.; Yon, G.H.; Kwon, D.Y.; Kim, Y.S.; Park, W.K.; Ryu, S.Y. A new specific BACE-1 inhibitor from the stembark extract of Vitis vinifera. Planta Med. 2009, 75, 537-740. [CrossRef]

29. Kim, Y.M.; Lee, E.W.; Eom, S.H.; Kim, T.H. Pancreatic lipase inhibitory stilbenoids from the roots of Vitis vinifera. Int. J. Food Sci. Nutr. 2014, 65, 97-100. [CrossRef]

30. Esatbeyoglu, T.; Ewald, P.; Yasui, Y.; Yokokawa, H.; Wagner, E.A.; Matsugo, S.; Winterhalter, P.; Rimbach, G. Chemical characterization, free radical scavenging, and cellular antioxidant and anti-inflammatory properties of a stilbenoid-rich root extract of Vitis vinifera. Oxid. Med. Cell. Longev. 2016, 2016, 11. [CrossRef]

31. Waffo-Teguo, P.; Krisa, S.; Richard, T.; Mérillon, J.M. Grapevine stilbenes and their biological effects. In Bioactive Molecules and Medicinal Plants; Chapter 2; Gopal Ramawat, K., Merillon, J.-M., Eds.; Springer: Berlin/Heidelberg, Germany, 2008; pp. 25-54.

32. Pantelić, M.M.; Dabić Zagorac, Č.D.; Ćirić, Ž.I.; Pergal, V.M.; Relić, J.D.; Todić, R.S.; Natić, M.M. Phenolic profiles, antioxidant activity and minerals in leaves of different grapevine varieties grown in Serbia. J. Food Compos. Anal. 2017, 62, 76-83. [CrossRef]

33. Barros, A.; Gironés-Vilaplana, A.; Teixeira, A.; Collado-González, J.; Moreno, A.D.; Gil-Izquierdo, A.; Rosa, E.; Domínguez-Perles, R. Evaluation of grape (Vitis vinifera L.) stems from Portuguese varieties as a resource of (poly)phenolic compounds: A comparative study. Food Res. Int. 2014, 65, 375-384. [CrossRef]

34. Makris, P.D.; Boskou, G.; Andrikopoulos, K.N.; Kefalas, P. Characterisation of certain major polyphenolic antioxidants in grape (Vitis vinifera cv. Roditis) stems by liquid chromatography-mass spectrometry. Eur. Food Res. Technol. 2008, 226, 1075-1079. [CrossRef]

35. Iriti, M.; Faoro, F. Bioactive chemicals and health benefits of grapevine products. In Bioactive Foods in Promoting Health: Fruits and Vegetables; Chapter 38; Watson, R., Preedy, V., Eds.; Academic Press: Cambridge, MA, USA, 2010; pp. 581-620.

36. Gindro, K.; Alonso-Villaverde, V.; Viret, O.; Spring, J.L.; Marti, G.; Wolfender, J.L.; Pezet, R. Stilbenes: Biomarkers of grapevine resistance to disease of high relevance for agronomy, oenology and human health. In Plant Defence: Biological Control. Progress in Biological Control; Chapter 2; Merillon, J.-M., Ramawat, K.G., Eds.; Springer Science \& Business Media B.V.: Berlin, Germany, 2012; Volume 2, pp. 25-54.

37. Spatafora, C.; Barbagallo, E.; Amico, V.; Tringali, C. Grape stems from Sicilian Vitis vinifera cultivars as a source of polyphenol-enriched fractions with enhanced antioxidant activity. LWT Food Sci. Technol. 2013, 54, 542-548. [CrossRef]

38. Jeandet, P.; Jacquot, C.; Parmentier, M.; Conreux, A.; Sbaghi, M.; Adrian, M.; Waffo-Téguo, P. Role of stilbene dehydrodimers ( $\delta$ - and $\varepsilon$-viniferins) in the Botrytis cinerea/grapevine interaction. In Macromolecules and Secondary Metabolites of Grapevine and Wines; Jeandet, P., Clément, C., Conreux, A., Eds.; Intercept Lavoisier: New York, NY, USA, 2007; pp. 105-110.

39. Waffo-Teguo, P.; Krisa, S.; Pawlus, D.A.; Richard, T.; Monti, J.P.; Me'rillon, J.M. Grapevine stilbenoids: Bioavailability and neuroprotection. In Natural Products: Phytochemistry, Botany and Metabolism of Alkaloids, Phenolics and Terpenes; Chapter 73; Gopal Ramawat, K., Mérillon, J.-M., Eds.; Springer: Berlin/Heidelberg, Germany, 2013; pp. 2275-2309.

40. Gorena, T.; Saez, V.; Mardones, C.; Vergara, C.; Winterhalter, P.; Von Baer, D. Influence of post-pruning storage on stilbenoid levels in Vitis vinifera. L. canes. Food Chem. 2014, 155, 256-263. [CrossRef] [PubMed]

41. Fujii, F.; He, Y.H.; Terashima, K.; Takaya, Y.; Niwa, M. Three new stilbeneoligomers from the roots of Vitis vinifera 'Kyohou'. Heterocycles 2005, 65, 2461-2469. 
42. Reniero, F.; Rudolph, M.; Angioni, A.; Bernreuther, A.; Cabras, P.; Mattivi, F. Identification of two stilbenoids from Vitis roots. VITIS 1996, 35, 125-127.

43. Martin, N.; Vesentini, D.; Rego, C.; Monteiro, S.; Oliveira, H.; Ferreira, B.R. Phaeomoniella chlamydospora infection induces changes in phenolic compounds content in Vitis vinifera. Phytopathol. Mediterr. 2009, 48, 101-116.

44. Rusjan, D.; Persic, M.; Likar, M.; Biniari, K.; Mikulic-Petkovsek, M. Phenolic responses to esca-associated fungi in differently decayed grapevine woods from different trunk parts of 'Cabernet Sauvignon'. J. Agric. Food Chem. 2017, 65, 6615-6624. [CrossRef] [PubMed]

45. Lambert, C.; Bisson, J.; Waffo-Téguo, P.; Papastamoulis, Y.; Richard, T.; Corio-Costet, M.F.; Mérillon, J.M.; Cluzet, S. Phenolics and their antifungal role in grapevine wood decay: Focus on the Botryosphaeriaceae family. J. Agric. Food Chem. 2012, 60, 11859-11860. [CrossRef]

46. Delgado-Torre, M.P.; Ferreiro-Vera, C.; Priego-Capote, F.; Pérez-Juan, M.P.; Luque de Castro, D.M. Comparison of accelerated methods for the extraction of phenolic compounds from different vine-shoot cultivars. J. Agric. Food Chem. 2012, 60, 3051-3060. [CrossRef]

47. Max, B.; Salgado, J.M.; Cortés, S.; Domínguez, J.M. Extraction of phenolic acids by alkaline hydrolysis from the solid residue obtained after prehydrolysis of trimming vine shoots. J. Agric. Food Chem. 2010, 58, 1909-1917. [CrossRef]

48. Sánchez-Gómez, R.; Zalacain, A.; Alonso, G.L.; Salinas, M.R. Effect of toasting on non-volatile and volatile vine-shoots low molecular weight phenolic compounds. Food Chem. 2016, 204, 499-505. [CrossRef]

49. Sánchez-Gómez, R.; Zalacain, A.; Alonso, G.L.; Salinas, M.R. Vine-shoot waste aqueous extracts for re-use in agriculture obtained by different extraction techniques: Phenolic, volatile, and mineral compounds. J. Agric. Food Chem. 2014, 62, 10861-10872. [CrossRef] [PubMed]

50. Sáez, V.; Gayoso, C.; Riquelme, S.; Pérez, J.; Vergara, C.; Mardones, C.; Von Baer, D. C18 core-shell column with in-series absorbance and fluorescence detection for simultaneous monitoring of changes in stilbenoid and proanthocyanidin concentrations during grape cane storage. J. Chromatogr. B 2018, 1074, 70-78. [CrossRef] [PubMed]

51. Lambert, C.; Richard, T.; Renouf, E.; Bisson, J.; Waffo-Téguo, P.; Bordenave, I.; Ollat, N.; Mérillon, J.M.; Cluzet, S. Comparative analyses of stilbenoids in canes of major Vitis vinifera L. cultivars. J. Agric. Food Chem. 2013, 61, 11392-11399. [CrossRef] [PubMed]

52. Houillé, B.; Besseau, S.; Delanoue, G.; Oudin, A.; Papon, N.; Clastre, M.; Simkin, J.A.; Guérin, L.; Courdavault, V.; Giglioli-Guivarch, N.; et al. Composition and tissue-specific distribution of stilbenoids in grape canes are affected by downy mildew pressure in the vineyard. J. Agric. Food Chem. 2015, 63, 8472-8477. [CrossRef]

53. Püssa, T.; Floren, J.; Kuldkepp, P.; Raal, A. Survey of grapevine Vitis vinifera stem polyphenols by Liquid Chromatography-Diode Array Detection-Tandem Mass Spectrometry. J. Agric. Food Chem. 2006, 54, 7488-7494.

54. Dias, C.; Domínguez-Perles, R.; Aires, A.; Teixeira, A.; Rosa, E.; Barros, A.; Saavedra, J.M. Phytochemistry and activity against digestive pathogens of grape (Vitis vinifera L.) stem's (poly)phenolic extracts. LWT Food Sci. Technol. 2015, 61, 25-32. [CrossRef]

55. Wallis, M.C.; Chen, J.C. Grapevine phenolic compounds in xylem sap and tissues are significantly altered during infection by Xylella fastidiosa. Phytopathology 2012, 102, 816-826. [CrossRef]

56. Yan, K.X.; Terashima, K.; Takaya, Y.; Niwa, M. A novel oligostilbene named (+)-viniferol A from the stem of Vitis vinifera 'Kyohou'. Tetrahedron 2001, 57, 2711-2715. [CrossRef]

57. Yan, K.X.; Terashima, K.; Takaya, Y.; Niwa, M. Two new stilbenetetramers from the stem of Vitis vinifera 'Kyohou'. Tetrahedron 2002, 58, 6931-6935. [CrossRef]

58. Ewald, P.; Delker, U.; Winterhalter, P. Quantification of stilbenoids in grapevine canes and grape cluster stems with a focus on long-term storage effects on stilbenoid concentration in grapevine canes. Food Res. Int. 2017, 100, 326-331. [CrossRef]

59. Schoedl, K.; Forneck, A.; Sulyok, M.; Schuhmacher, R. Optimization, in-house validation, and application of a Liquid Chromatography_Tandem Mass Spectrometry (LC_MS/MS)-based method for the quantification of selected polyphenolic compounds in leaves of grapevine (Vitis vinifera L.). J. Agric. Food Chem. 2011, 59, 10787-10794. [CrossRef] [PubMed] 
60. Griesser, M.; Weingart, G.; Schoedl-Hummel, K.; Neumann, N.; Becker, M.; Varmuza, K.; Liebner, F.; Schuhmacher, R.; Forneck, A. Severe drought stress is affecting selected primary metabolites, polyphenols, and volatile metabolites in grapevine leaves (Vitis vinifera cv. Pinot noir). Plant Physiol. Biochem. 2015, 88, 17-26. [CrossRef] [PubMed]

61. Mattivi, F.; Vrhovsek, U.; Malacarne, G.; Masuero, D.; Zulini, L.; Stefanini, M.; Moser, C.; Velasco, R.; Guella, G. Profiling of resveratrol oligomers, important stress metabolites, accumulating in the leaves of hybrid Vitis vinifera (Merzling $\times$ Teroldego) genotypes infected with Plasmopara viticola. J. Agric. Food Chem. 2011, 59, 5364-5375. [CrossRef] [PubMed]

62. Pezet, R.; Perret, C.; Jean-Denis, J.B.; Tabacchi, R.; Gindro, K.; Viret, O. $\delta$-Viniferin, a resveratrol dehydrodimer: One of the major stilbenes synthesized by stressed grapevine leaves. J. Agric. Food Chem. 2003, 51, 5488-5492. [CrossRef] [PubMed]

63. Choi, S.J. The Identification of stilbene compounds and the change of their contents in UV-irradiated grapevine leaves. Korean J. Hortic Sci. 2011, 29, 374-381.

64. Tř́íska, J.; Vrchotová, N.; Olejníčková, J.; Jílek, R.; Sotolář, R. Separation and identification of highly fluorescent compounds derived from trans-resveratrol in the leaves of Vitis vinifera infected by Plasmopara viticola. Molecules 2012, 17, 2773-2783. [CrossRef]

65. Braidot, E.; Zancani, M.; Petrussa, E.; Peresson, C.; Bertolini, A.; Patui, S.; Macrì, F.; Vianello, A. Transport and accumulation of flavonoids in grapevine (Vitis vinifera L.). Plant Signal. Behav. 2008, 3, 626-632. [CrossRef]

66. Tartaglione, L.; Gambuti, A.; De Cicco, P.; Ercolano, G.; Ianaro, A.; Taglialatela-Scafati, O.; Moio, L.; Forino, M. NMR-based phytochemical analysis of Vitis vinifera cv Falanghina leaves. Characterization of a previously undescribed biflavonoid with antiproliferative activity. Fitoterapia 2018, 125, 13-17. [CrossRef]

67. Takaya, Y.; Terashima, K.; Yan, K.X.; Niwa, M. (+)-Viniferol D, a new stilbenetrimer from the stem of Vitis vinifera 'Kyohou'. Heterocycles 2003, 60, 1433-1439. [CrossRef]

68. Becker, L.; Carré, V.; Poutaraud, A.; Merdinoglu, D.; Chaimbault, P. MALDI mass spectrometry imaging for the simultaneous location of resveratrol, pterostilbene and viniferins on grapevine leaves. Molecules 2014, 19, 10587-10600. [CrossRef]

69. Jordão, A.M.; Ricardo-da-Silva, J.M.; Laureano, O. Evolution of proanthocyanidins in bunch stems during berry development (Vitis vinifera L.). Vitis 2001, 40, 17-22.

70. Bruisson, S.; Maillot, P.; Schellenbaum, P.; Walter, B.; Gindro, K.; Deglène-Benbrahim, L. Arbuscular mycorrhizal symbiosis stimulates key genes of the phenylpropanoid biosynthesis and stilbenoid production in grapevine leaves in response to downy mildew and grey mould infection. Phytochemistry 2016, 131, 92-99. [CrossRef] [PubMed]

71. Bavaresco, L.; Fregoni, C.; Gonçalves, M.I.; Vezzulli, S. Physiology \& molecular biology of grapevine stilbenes: An update. In Grapevine Molecular Physiology \& Biotechnology, 2nd ed.; Roubelakis-Angelakis, K.A., Ed.; Springer Science \& Business Media B.V.: Dordrecht, The Netherlands, 2009; pp. 341-364.

72. Montero, L.; Sáez, V.; Von Baer, D.; Cifuentes, A.; Herrero, M. Profiling of Vitis vinifera L. canes (poly)phenolic compounds using comprehensive two-dimensional liquid chromatography. J. Chromatogr. A 2018, 1536, 205-215. [CrossRef] [PubMed]

73. Anđelković, M.; Radovanović, B.; Anđelković, M.A.; Radovanović, V. Phenolic compounds and bioactivity of healthy and infected grapevine leaf extracts from red varieties Merlot and Vranac (Vitis vinifera L.). Plant Foods Hum. Nutr. 2015, 70, 317-323. [CrossRef] [PubMed]

74. Karvela, E.; Makris, P.D.; Kalogeropoulos, N.; Karathanos, T.V. Deployment of response surface methodology to optimise recovery of grape (Vitis vinifera) stem polyphenols. Talanta 2009, 79, 1311-1321. [CrossRef] [PubMed]

75. Topalović, A.; Mikulič-Petkovšek, M.; Perović, N.; Trifunović, S.; Knežević, M. Phenolic composition of the leaf of grapevine cv. cardinal. Agr. Forest. 2012, 52, 5-15.

76. Huang, Y.F.; Cheynier, V.; Terrier, N. Shedding light on the black boxes of the proanthocyanidin pathway with grapevine. In Recent Advances in Polyphenol Research, 1st ed.; Chapter 7; Cheynier, V., Sarni-Manchado, P., Quideau, S., Eds.; John Wiley \& Sons, Ltd.: Hoboken, NJ, USA, 2012; Volume 3, pp. 161-190.

77. Cui, Z.H.; Bi, W.L.; Hao, X.Y.; Li, P.M.; Duan, Y.; Walker, M.A.; Xu, Y.; Wang, Q.C. Drought stress enhances up-regulation of anthocyanin biosynthesis in grapevine leafroll-associated virus 3-infected in vitro grapevine (Vitis vinifera) leaves. Plant Dis. 2017, 101, 1606-1615. [CrossRef] 
78. Caramanico, L.; Rustioni, L.; De Lorenzis, G. Iron deficiency stimulates anthocyanin accumulation in grapevine apical leaves. Plant Physiol. Biochem. 2017, 119, 286-293. [CrossRef]

79. Schneider, E.; Heydt, V.H.; Esperester, A. Evaluation of polyphenol composition in red leaves from different varieties of Vitis vinifera. Planta Med. 2008, 74, 565-572. [CrossRef]

80. Park, H.J.; Lim, C.E.; Park, C.W.; Cha, H.C. Analysis of flavonols extracted from leaves of various grapevine cultivars by HPLC. Hortic. Environ. Biot. 2004, 45, 138-142.

81. Chitarrini, G.; Zulini, L.; Masuero, D.; Vrhovsek, U. Lipid, phenol and carotenoid changes in 'Bianca' grapevine leaves after mechanical wounding: A case study. Protoplasma 2017, 254, 2095-2106. [CrossRef] [PubMed]

82. Vezzulli, S.; Malacarne, G.; Masuero, D.; Vecchione, A.; Dolzani, C.; Goremykin, V.; Mehari, H.Z.; Banchi, E.; Velasco, R.; Stefanini, M.; et al. The Rpv3-3 haplotype and stilbenoid induction mediate downy mildew resistance in a grapevine interspecific population. Front. Plant Sci. 2019, 10, 234. [CrossRef] [PubMed]

83. Luque-Rodríguez, J.M.; Pérez-Juan, P.; Luque de Castro, M.D. Extraction of polyphenols from vine shoots of Vitis vinifera by superheated ethanol-water mixtures. J. Agric. Food Chem. 2006, 54, 8775-8781. [CrossRef] [PubMed]

84. Schoedl, K.; Schuhmacher, R.; Forneck, A. Studying the polyphenols of grapevine leaves according to age and insertion level under controlled conditions. Sci. Hortic. 2012, 141, 37-41. [CrossRef]

85. Kocsis, M.; Abrankó, L.; Ayaydin, F.; Csepregi, K.; Papp, N.; Teszlák, P.; Jakab, G. Main leaf polyphenolic components of berry color variant grapevines and their acclimative responses to sunlight exposure. Appl. Sci. 2015, 5, 1955-1969. [CrossRef]

86. Martín, L.; Fontaine, F.; Castañoa, J.F.; Songy, A.; Roda, R.; Vallet, J.; Ferrer-Gallego, R. Specific profile of Tempranillo grapevines related to Esca-leaf symptoms and climate conditions. Plant Physiol. Biochem. 2019, 135, 575-587. [CrossRef]

87. Farhadi, K.; Esmaeilzadeh, F.; Hatami, M.; Forough, M.; Molaie, R. Determination of phenolic compounds content and antioxidant activity in skin, pulp, seed, cane and leaf of five native grape cultivars in West Azerbaijan province, Iran. Food Chem. 2016, 199, 847-855. [CrossRef]

88. Taware, B.P.; Dhumal, N.K.; Oulkar, P.D.; Patil, H.S.; Banerjee, K. Phenolic alterations in grape leaves, berries and wines due to foliar and cluster powdery mildew infections. Int. J. Pharma Bio. Sci. 2010, 1, 1-14.

89. Vrhovsek, U.; Malacarne, G.; Masuero, D.; Zulini, I.; Guella, G.; Stefanini, M.; Velasco, R.; Mattivi, F. Profiling and accurate quantification of trans-resveratrol, trans-piceid, trans-pterostilbene and 11 viniferins induced by Plasmopara viticola in partially resistant grapevine leaves. Aust. J. Grape wine Res. 2012, 18, 11-19. [CrossRef]

90. Mikeš, O.; Vrchotová, N.; Tříska, J.; Kyseláková, M.; Šmidrkal, J. Distribution of major polyphenolic compounds in vine grapes of different cultivars growing in south Moravian vineyards. Czech J. Food Sci. 2008, 26, 182-189. [CrossRef]

91. Piñeiro, Z.; Guerrero, R.F.; Fernández-Marin, M.I.; Cantos-Villar, E.; Palma, M. Ultrasound-assisted extraction of stilbenoids from grape stems. J. Agric. Food Chem. 2013, 61, 12549-12556. [CrossRef] [PubMed]

92. Bavaresco, L.; Mattivi, F.; De Rosso, M.; Flamini, R. Effects of elicitors, viticultural factors, and enological practices on resveratrol and stilbenes in grapevine and wine. Mini-Rev. Med. Chem. 2012, 12, 1366-1381. [PubMed]

(C) 2020 by the authors. Licensee MDPI, Basel, Switzerland. This article is an open access article distributed under the terms and conditions of the Creative Commons Attribution (CC BY) license (http://creativecommons.org/licenses/by/4.0/). 